\title{
LA PREJUDICIALIDAD EN EL PROCESO CIVIL
}

\section{PRELIMINARY RULINGS IN THE CIVIL PROCEDURE}

\author{
Alejandro Romero Seguel
}

\begin{abstract}
RESUMEN: Este trabajo aborda el tema de la prejudicialidad en el proceso civil chileno, con especial enfásis en aquellos temas que, por su conexión lógica y jurídica con el objeto proceso, deben ser decididos, por el mismo juez u otro tribunal, antes de la sentencia de fondo del conflicto sometido a su conocimiento. Para el desarrollo sistemático del tema se utilizan los criterios que están aceptados en nuestro sistema jurídico, donde que según el grado de obligatoriedad o discrecionalidad en la competencia asignada al mismo juez u otro que debe pronunciarse, se diferencia entre cuestiones prejudiciales relativas y absolutas; las cuestiones prejudiciales devolutivas y no devolutivas; las cuestiones prejudiciales civiles y las penales.
\end{abstract}

Palabras clave: Prejudicialidad, Competencia, Cosa juzgada.

ABSTRACT: This article explores the subject of preliminary rulings in the Chilean Civil Procedure. Namely, it is focused on those issues which, due to their logical and legal connection to the object of the process, must be decided by the same or a different Court, before the final and substantial judgement is made. In order to provide a systemic development of the subject, only criteria accepted by the legal system will be used. Preliminary rulings can be either relative or absolute, depending on whether the power conferred to the judge is mandatory or discretionary. They can also be divided into devolutive and non devolutive, and into civil and criminal.

Key words: Preliminary rulings, Jurisdiction, Res iudicata.

\section{EXPLICACIÓN PRELIMINAR}

La prejudicialidad constituye un tema clásico y a la vez complejo en el estudio del derecho procesal. La mayor dificultad para su análisis proviene de la convergencia de elementos de derecho sustantivo y procesal en los problemas que suscita. Como lo sentenciaba Gómez Orbaneja, en palabras que no pierden vigencia, la prejudicialidad forma parte de uno de los sectores menos aclarados y resueltos en la ciencia jurídica de todos los países ${ }^{1}$. Lo anterior se comprueba por la diversidad de explicaciones teóricas y soluciones legales que existen sobre esta materia.

En un análisis etimológico, la palabra prejudicial deriva de la voz latina praejudicium, que significa 'prejuicio, juicio previo o prematuro' (de 'prae-' 'antes', judicium 'juicio'). Sin embargo, esta aproximación no clarifica el alcance de la institución en comento,

\footnotetext{
* Profesor de Derecho Procesal de la Universidad de los Andes (Santiago de Chile). Doctor en Derecho, Universidad de Navarra. Licenciado en Ciencias Jurídicas y Sociales de la Universidad de Valparaíso. Decano de la Facultad de Derecho Universidad de los Andes. Dirección postal: Av. San Carlos de Apoquindo 2200, Las Condes, Santiago, Chile. Correo electrónico: aromero@uandes.cl

1 Cfr. Gómez (1947) T. I, p. 134.
} 
que como se explicará en este trabajo se proyecta en una variedad de actuaciones e instituciones procesales.

El tema ya estaba presente en el proceso romano, pero como ha ocurrido con tantas instituciones jurídicas, ha seguido una evolución que se explica por un cúmulo de factores ${ }^{2}$.

En un plano general, la reglamentación de esta materia impone al legislador realizar varias opciones técnicas, dentro de un amplio marco de posibilidades. Entre los temas que determinan los rasgos del sistema de prejudicialidad en un determinado ordenamiento jurídico están: los atingentes al mecanismo de distribución de competencia entre los distintos jueces que conforman el órgano jurisdiccional; la eficacia que la ley le atribuye a un fallo en relación a la intervención de otros jueces y tribunales que integran la jurisdicción, en procesos posteriores o que se tramitan simultáneamente; el régimen de ejercicio de la acción civil y penal; la posibilidad de suspender obligatoria o facultativamente la tramitación de un proceso, en espera de la conclusión de otro, cuando entre los objetos procesales se presentan relaciones de conexión o de prejudicialidad.

En el plano doctrinal, para tratar de delimitar qué es una cuestión prejudicial han coexistido varias explicaciones ${ }^{3}$.

Desde una perspectiva general, la prejudicialidad aludiría a todas las cuestiones que se deben resolver antes de decidir sobre el objeto del proceso. Si se utiliza este prisma, surge la dificultad de poder calificar como tal a una amplia gama de asuntos donde está presente este elemento cronológico de juzgamiento previo a la decisión final. Así, tendría tal carácter desde la promoción de un incidente en un juicio, hasta la formulación de una cuestión prejudicial propiamente tal.

En cambio, en un sentido restringido, la prejudicialidad surgiría en ciertos temas que, por su conexión lógica y jurídica con el objeto proceso, deben ser fallados, por el mismo juez u otro tribunal, antes de la decisión de fondo del conflicto sometido a su conocimiento. Dicho asunto, a su vez, tendría un grado de autonomía que permitiría ser resuelto en otro proceso, con efecto de cosa juzgada ${ }^{4}$. En palabras de Cappelletti, el prae-judicium

\footnotetext{
${ }^{2}$ Como lo describe Robles Reyes, "a esta incidencia de un proceso sobre otro, atribuidos ambos a órganos distintos, y muy especialmente al supuesto de la concurrencia de un mismo procedimiento de la jurisdicción penal y de la civil, es a lo que se llamó desde la antigua Roma prejudicialidad penal o praeiudicia. Pero esta interesante problemática presenta un contenido distinto según el periodo de la Historia de Roma que contemplemos y el sistema procesal aplicable en ese momento histórico. Desde el principio de los tiempos se han entrecruzado cuestiones civiles y penales en el planteamiento y resolución del litigio y, por tanto, desde que el Derecho Romano fue tal, los magistrados y jueces debieron resolver litigios dando preferencia a las cuestiones civiles, a las penales, o resolver ambas en su conjunto" [Robles (2003) p. 20]. A modo de conclusión el mismo autor indica que "(...) las soluciones recogidas en diversos textos, sobre todo de la época imperial, denotan una ausencia de reglas fijas o normas claras que resolviesen el problema. Incluso en la época de la extraordinaria cognitio tampoco se resolvió del todo el problema de la prejudicialidad en temas civiles, como muestran las soluciones recogidas en el Código Justinianeo" Robles (2003) p. 20.

${ }^{3}$ Una síntesis de la discusión doctrinal, en Reynal (2006) pp. 37-53. Sobre el tema, entre la abundante bibliografía, Menestrina (1904) pp. 1-218; Aguilera (1917) pp. 1-529; Alsina (1959) pp. 66-69; Rosenblant, (2000) pp. 15-96; GonzÁlez (2002) pp. 44-60.; Morcillo (2007) pp. 10-50; Pérez (1982) pp. 28-29; Рroto (2006) pp. 67-68; Picardi (2006) pp. 81-84; Calamandrei (1996) vol. II., pp. 301-302; Mattirolo (1930) pp. 761-769; ChiOvenda (1977) T. II, p. 731.

${ }^{4}$ En un trabajo clásico sobre el tema, ALSINA indica que debe tratarse de "un juicio autónomo ante otro tribunal, sobre una cuestión sustancial independiente de la que motiva la Litis en el juicio, lo que permite incluir los asuntos tramitados ante jueces de la misma jurisdicción" (Alsina (1959) pp. 66-69). En similar orientación, ReYnAL puntualiza que
} 
es la decisión de una causa autónoma, aunque prejudicial, respecto de la causa principal: es decir, por definición, la decisión de una causa que normalmente hubiera podido plantearse también por sí sola, como causa principal de un juicio separado5.

En nuestra opinión, lo que introduce al proceso una cuestión prejudicial proviene de alguna situación de derecho sustantivo, que obliga a emitir un pronunciamiento que forma parte del objeto del proceso. Tema diverso es el de la competencia para resolver esta materia, que depende del sistema que la ley haya establecido delimitando el carácter absoluto, relativo, devolutivo o no devolutivo de las cuestiones prejudiciales.

\section{LA VARIEDAD DE CRITERIOS PARA SU ESTUDIO}

La complejidad para examinar la prejudicialidad se acentúa por la variedad de criterios propuestos por la doctrina para su estudio.

Por estar aceptados explícita o implícitamente en nuestro sistema jurídico, resulta de interés considerar los siguientes:

- Según el grado de obligatoriedad o discrecionalidad en la competencia asignada al mismo juez u otro que debe pronunciarse, se diferencia entre cuestiones prejudiciales relativas y absolutas.

- Según a quien se encomienda su resolución, se distingue entre cuestiones prejudiciales devolutivas y no devolutivas.

- Según el acto procesal donde incide, las cuestiones prejudiciales pueden ser relativas a la acción o a la sentencia.

- Según la naturaleza de la jurisdicción donde surgen, se diferencia entre cuestiones prejudiciales homogéneas y heterogéneas ${ }^{6}$.

- Según la justificación en las reglas de la lógica que deben sustentar el pronunciamiento de una sentencia o por razones jurídicas presentes en la decisión de un determinado conflicto, se distingue entre prejudicialidad en sentido lógico y prejudicialidad en sentido jurídico ${ }^{7}$. Desde el punto de vista lógico, como lo indica Lemmo, "la prejudicialidad denota la prioridad que tendría un juicio respecto de otro" ${ }^{8}$. En cambio, en sentido técnico jurídico, la prejudicialidad surge cuando para un deter-

\footnotetext{
"el fenómeno de la prejudicialidad implica la existencia de una cuestión prejudicial y de una cuestión principal, dado que un asunto no es prejudicial en sí mismo, sino que con relación a otro” [REYNAL (2006) p. 32].

5 Cfr. Cappelletti (1968) pp. 29-30.

6 En explicación de MorCillo “(...) el criterio conforme al cual se habla de cuestiones prejudiciales homogéneas o heterogéneas es el de la identidad de la cuestión prejudicial con la del asunto principal. De este modo, si ambos asuntos -el principal y el prejudicial- tienen la misma naturaleza o, dicho de otra manera, pertenecen al mismo orden jurisdiccional, se habla de prejudicialidad homogénea. Por el contrario, cuando el conocimiento de los objetos que constituyen la cuestión prejudicial y el tema principal se atribuye a distintos órdenes jurisdiccionales, entonces la doctrina se refiere a las cuestiones prejudiciales heterogéneas" [MorCiLlo (2007) pp. 49-50].

7 Esta distinción tiene como referencia común el trabajo de Menestrina (1872-1961), Menestrina (1904) pp. 86-120. Este jurista italiano detentó la cátedra de derecho procesal civil en lengua italiana en la Universidad de Innsbruck, Austria. Siguiendo sus pasos, entre otros, utilizan esta diferenciación, SATTA (1971), T, I, p. 45.

8 LEMMO (1991) T. XVI, p. 1.
} 
minado juzgamiento se requiere la resolución de un tribunal que actúa en otro ámbito competencial, suspendiendo el procedimiento principal hasta que dicha cuestión se resolviere por sentencia firme 9 , o del mismo tribunal que conoce de la cuestión prejudicial, cuando el asunto forma parte de su competencia.

- Según el proceso donde se reglamenta, se distingue entre cuestiones prejudiciales civiles, penales, constitucionales, administrativas y laborales. Por herencia de la codificación decimonónica, el mayor desarrollo del tema se encuentra en la regulación de las cuestiones prejudiciales civiles y penales, cuyo alcance se examina más adelante.

La prejudicialidad constitucional se puede presentar en la actuación del Tribunal Constitucional, específicamente, en su competencia para conocer y fallar acerca de la inaplicabilidad de normas legales que se impugnan por estimarse contrarias a la Constitución (art. 93 No 6 CPR). Como señala Gómez Bernales, la inaplicabilidad funciona como control de interpretaciones o significados de los enunciados (normas) aplicables a casos ${ }^{10}$. La existencia de un proceso autónomo, distinto del procedimiento o gestión donde incide la sentencia de inaplicabilidad, permite calificar a esta actuación del Tribunal Constitucional como prejudicial ${ }^{11}$.

La prejudicialidad administrativa, por su parte, se presenta en aquellos casos donde un órgano de esa naturaleza, actuando dentro de su competencia, emite un pronunciamiento que, por su conexión lógica y jurídica con el objeto del proceso, debe ser resuelto antes de pronunciar la sentencia. Esta proyección se ha hecho cada vez más frecuente por la ampliación de la actividad jurídica de Estado, que ha creado diversos órganos cuyos pronunciamientos jurídicos inciden prejudicialmente en el resultado de procesos jurisdiccionales. El legislador del siglo XIX no previó normas de prejudicialidad para lograr una coordinación general entre la actuación de la Administración y de los órganos jurisdiccionales, salvo la remisión al juicio de cuentas fiscales, en los términos que admite el art. 173 inc. $2^{\circ}$ del Código Orgánico de Tribunales. A ese caso se han sumado otras manifestaciones contenidas en leyes especiales, que admiten que la declaración del derecho en sede administrativa sea considerada en la decisión del objeto de un proceso posterior.

El procedimiento laboral no contiene una reglamentación general de la prejudicialidad. Este defecto ha sido una constante desde la promulgación del Código del Trabajo de 1931, pero su omisión ha quedado en evidencia en el último tiempo, especialmente, para abordar la problemática de la responsabilidad por subcontratación (art. 183 B del Código de trabajo) ${ }^{12}$ y en los conflictos surgidos en relación a la extensión del contrato de trabajo

\footnotetext{
9 Esta definición surge del art. 171 del Código Procesal Penal.

10 Gómez Bernales (2005) p. 669.

11 Tema diverso, que supera el objeto de este estudio, es determinar el grado de vinculación que logran en la decisión del caso concreto las declaraciones de inaplicabilidad. Un estudio de los fallos proyectado a casos, cfr. GÓMEz BERNALES (2013) pp. 17-277; Silva (2013) pp. 185-198.

12 A modo ilustrativo, Silva con Alvarado y Salmones Caleta Bay S.A. (2012), al señalar que: "Octavo: Que, en consecuencia, al establecerse en autos que el empleador directo del actor no fue demandado, quedando en consecuencia, la sola presencia o emplazamiento del dueño de la obra como ente demandado en el presente juicio laboral, no erige a este último en legítimo contradictor para sustanciar y resolver de esta forma las materias de-
} 
y las dificultades que surgen con el derecho de patentes en el caso de invenciones surgidas durante la vigencia de la relación laboral ${ }^{13}$. Excepcionalmente, en este ámbito operan algunas hipótesis de prejudicialidad administrativa, siendo una de las más relevantes la calificación de un hecho como accidente del trabajo por la entidad competente, cuyos efectos se proyectan en la decisión de procesos civiles o laborales vinculados a esa materia ${ }^{14}$.

\section{PREJUDICIALIDAD, ORGANIZACIÓN JURISDICCIONAL Y DECISIONES CONTRADICTORIAS}

La prejudicialidad es una institución que también se relaciona con la organización jurisdiccional y con una pretendida unidad del ordenamiento jurídico ${ }^{15}$. Su correcta utilización debería asegurar que, en la resolución de los conflictos asignados a los diversos jueces

batidas y, en tales condiciones, no resulta ser, como emplazado de modo singular, legitimado pasivo de la acción incoada en esta sede. La facultad de traer a juicio al demandado requería del concurso, también como demandado, del empleador directo, lo que según se ha visto se desprende en forma nítida del texto del artículo 183-B del Código del Trabajo que rige para la situación en análisis, especialmente de su inciso cuarto (...) Noveno: Que de acuerdo a lo precedentemente analizado y en razón de haber quedado excluido de la controversia el empleador directo -al concluirse que no fue demandado en autos, y por haberse sustanciado el proceso solo en contra del dueño de la obra, se ha faltado a una condición procesal previa e ineludible prevista expresamente por la ley para traer a juicio a un tercero ajeno a la relación laboral-, no cabe sino concluir que la acción así sustanciada no ha podido prosperar resultando inoficioso incurrir en otro tipo de consideraciones en torno a las alegaciones y pruebas vertidas y allegadas por quienes figuraron como litigantes. Con anterioridad, en igual sentido, Morales Riquelme, Jorge con I. Municipalidad de Pucón (2010), estableciendo que "DECIMOSEXTO: Que, en el contexto de lo que se ha dejado establecido, al concluir y así decidirlo los jueces del grado, que en razón de haber procedido el actor a excluir de la demanda al empleador directo y dirigir la acción únicamente en contra de la entidad dueña de la obra se ha faltado a una condición procesal previa e ineludible prevista por la ley -como presupuesto indispensable para traer a juicio al tercero ajeno a la relación laboral- y, en razón de esa conclusión revocando el fallo de primer grado negaron lugar a la demanda así incoada, no han incurrido en infracción de los incisos primero y cuarto del artículo 183-B del Código del Trabajo, sino que por el contrario, han dado correcta aplicación a los textos aludidos, motivo por el que el recurso de casación en el fondo deducido por la parte demandante deberá, necesariamente, ser desestimado" (Morales Riquelme, Jorge cl I. Municipalidad de Pucón).

${ }^{13}$ El problema surge en relación a la intervención del Instituto Nacional de Propiedad Industrial (INAPI) y los juzgados con competencia laboral. Ilustra el problema la sentencia Cárdenas Triviño con Corporación Universidad de Concepción (2011). Para mayores antecedentes cfr. SIERRA (2013) pp. 133-136.

${ }^{14}$ Esta hipótesis de prejudicialidad administrativa se da en la calificación de los accidentes del trabajo, que se hace mediante una Resolución de la entidad administradora, de acuerdo a lo establecido en el artículo 76 letras "e)" y "f)" del D.S. No 101/1968, en relación a la contingencia cubierta por la Ley No 16.744, que regula las prestaciones del Sistema de Seguridad Social por accidentes del trabajo y enfermedades profesionales.

15 Como lo describe De La Oliva, “(...) la prejudicialidad tiene razón de ser en virtud de dos factores: la unidad del ordenamiento jurídico, de un lado y, de otro, la especialización de los órganos jurisdiccionales. Este tópico es cierto en el sentido de que una organización jurisdiccional en que no existiese más de un tipo de órgano jurisdiccional con todas las competencias civiles, penales, contencioso-administrativas y laborales, carecería de sentido preguntarse si el órgano penal ha de resolver también los puntos civiles, laborales o administrativos o, por el contrario, ha de deferir su conocimiento a otros órganos jurisdiccionales (...)". "Pero la prejudicialidad es, además, de un problema de distribución de trabajo enjuiciador, un fenómeno de método enjuiciador -la necesidad de juicios previos, que preparan otro enjuiciamiento posterior-, en el que juega un papel de relieve otro elemento, determinante de la existencia de auténticas cuestiones prejudiciales”. DE lA Oliva (2010) p. 254. 
y tribunales que componen el órgano jurisdiccional, no surjan decisiones contradictorias o que no tengan una justificación jurídica ${ }^{16}$.

Nuestra primera Ley de Organización y Atribuciones de los Tribunales de Justicia, de 1875, no consideró explícitamente a la prejudicialidad como un criterio de coordinación entre los jueces y tribunales componentes del Poder Judicial ${ }^{17}$. El legislador consideró que con la aplicación los factores de asignación de competencia vinculados al fuero, la materia, la cuantía y el territorio, se lograría una actuación armónica entre los distintos componentes de nuestro primer modelo de administración de justicia.

Transcurrido más de un siglo desde la instalación del sistema anterior, la evolución institucional ha llevado a una mayor complejidad en el funcionamiento del órgano jurisdiccional, tanto por la ampliación en el número de jueces y tribunales como en la distribución de sus competencias. Esta realidad se aprecia claramente en la actual redacción del art. 5 del Código Orgánico de Tribunales, al distinguir entre los jueces y tribunales que integran el Poder Judicial como tribunales ordinarios o especiales y los que conforman la difusa realidad de "los demás tribunales especiales"18.

En este escenario de variedad competencial, la actuación coordinada de los diversos jueces y tribunales debería considerar la institución jurídica que estamos examinando, atendido que la solución de los conflictos intersubjetivos puede desenvolverse dentro de un conjunto complejo de relaciones de hecho y de derecho ${ }^{19}$. Como lo indica Fenech, "la prejudicialidad es un fenómeno jurídico de carácter general producido por la relación y conexión entre las diversas ramas del Derecho y la unidad del ordenamiento jurídico, en el que no hay compartimientos estancos" 20 .

Como se anticipaba, al reglamentar la competencia el legislador no ha considerado, de un modo general, la prejudicialidad como un factor más en la distribución del trabajo judicial. Esta omisión se ha hecho patente en las últimas décadas al proliferar jueces, tribunales y órganos administrativos, que al decidir acerca de temas lógica y jurídicamente

\footnotetext{
16 Sobre el tema de la contradicción, con abundante bibliografia, cfr. CARRETTA (2013) pp. 27-72.

${ }^{17} \mathrm{El}$ art. $5^{\circ}$ de la Ley de Organización y Atribuciones de los Tribunales de Justicia, disponía que, "a los tribunales que establece la presente ley estará sujeto el conocimiento de todos los asuntos judiciales que se promuevan en el orden temporal dentro del territorio de la República, cualquiera que sea la naturaleza o la calidad de las personas que en ellas intervengan, con las solas excepciones siguientes (...)”. Tales excepciones eran: " $1^{\circ}$ Las acusaciones constitucionales. $2^{\circ}$ Las causas cuyo conocimiento corresponde al Consejo de Estado; $3^{\circ}$ Las causas sobre abusos de la libertad de imprenta; $4^{\circ}$ Las causas por delitos meramente militares o que consistan en la infracción de las leyes especiales del ramo; $5^{\circ}$ Las causas por delitos comunes que comentan los militares estando en campaña o en actos del servicio militar, o dentro de sus cuarteles, todas las cuales quedarán sujetas al conocimiento de los tribunales que el Código designa. $6^{\circ}$ Las causas sobre cuentas fiscales, de las cuales conocerán la Contraloría Mayor i el Tribunal Superior de Cuentas; $7^{\circ}$ Las causas sobre cuentas municipales. $8^{\circ}$ Las causas que versen sobre validez o nulidad de un matrimonio no católico o sobre divorcio temporal o perpetuo entre cónyuges casados conforme a ritos no católicos. Las penas que la autoridad eclesiástica imponga en virtud de su jurisdicción espiritual no se entenderá que dejan de ser espirituales porque produzcan efectos temporales, como por ejemplo, la suspensión o privación de un beneficio eclesiástico, o de sus frutos.

18 Dentro de las explicaciones de este complejo sistema, entre otros, cfr. Bermúdez (2014) pp. 477-580; VERgara (2011) pp. 37-51; Lara (2011) pp. 65-92; Aróstica (2008) pp. 85-103.

19 Sobre el tema $c f r$. Carpintero (2012) pp. 73-86.

20 FeneCh (1978) p. 365.
} 
relacionados pueden incidir prejudicialmente en la resolución de otro litigio pendiente o iniciado con posterioridad.

Desde otro punto de vista, la interpretación y aplicación del derecho en muchas situaciones se debe hacer a partir de reglamentaciones que no se excluyen automáticamente, dentro de fenómenos que ya resultan normales en nuestro sistema jurídico, como la inflación legislativa o la descodificación ${ }^{21}$.

En este orden de ideas, es conveniente indicar que la prejudicialidad tiene límites que evitan asignarle una extensión que supere su ámbito natural, que no es otro que racionalizar la actuación de los distintos jueces y tribunales que componen el órgano jurisdiccional.

En primer lugar, no se puede calificar como un problema de prejudicialidad la circunstancia que sobre unos mismos hechos puedan surgir una disparidad de soluciones en el juzgamiento realizado en distintos procesos por un juez o tribunal. La diversidad de posibles respuestas jurídicas se explica, entre otras causas, por la existencia de una variedad de regímenes jurídicos que pueden concurrir a reglamentar un mismo hecho acaecido en la realidad.

En algunos casos esta variedad de decisiones está admitida expresamente en la ley, como ocurre, entre otras hipótesis, con el art. 55 de la Ley de Mercado de Valores No 18.045; allí se dispone que una persona que infrinja las disposiciones contenidas en esa ley, sus normas complementarias o las normas que imparta la Superintendencia de Valores y Seguros ocasionado daño a otro puede ser obligada a la indemnización de los perjuicios, sin que ello obste a las sanciones administrativas o penales que pudiere corresponderle. Así, en el ámbito sancionatorio el tema puede ser objeto de una investigación realizada por la $\mathrm{Su}$ perintendencia referida; $y$, al mismo tiempo, para efectos de verificar la comisión de algún ilícito penal el mismo hecho puede ser indagado por el Ministerio Público, ello sin perjuicio de la limitación que corresponda hacer por aplicación del principio del non bis in idem, para evitar una acumulación de sanciones en relación a una misma conducta ${ }^{22}$. Junto a lo anterior, también podría haberse iniciado un proceso civil, con el objeto de hacer efectiva la eventual responsabilidad patrimonial, si los actos realizados han producido un daño patrimonial y concurren los demás requisitos legales para ello.

También es factible que un mismo hecho pueda tener diversas consecuencias jurídicas, según corresponda a la responsabilidad civil y la penal. Como lo expone Barros, "aunque en épocas tempranas parecen no haber estado distantes, la responsabilidad civil y la responsabilidad penal han llegado a ser distintas entre sí por sus fines y condiciones de imposición. La tendencia a la separación se ha acentuado en épocas recientes. Por una parte, se ha llegado a construir una teoría del delito extremadamente refinada, que se ha caracterizado por la definición rigurosa de los requisitos para hacer procedente la sanción penal, con el resultado de que la doctrina del delito actúa como un límite a la imposición de la pena, mientras que la responsabilidad civil, por el contrario, la tendencia ha sido a la expansión”23.

21 La solución a este tipo de problemas se obtiene, entre otras vías, acudiendo a los criterios provenientes de la temática de los concurso de normas y de acciones, que contribuyen a evitar que lo que afirme un juez en una sentencia no sea contradicho, sin justificación jurídica, en otro proceso. Un estudio del tema, cfr. ROMERO (2013) pp. 207-250.

22 Sobre el tema, cfr. CANo (2001) pp. 191-249; De León (1998) pp. 229-447; Cordero (2014) pp. $264-266$.

23 Barros (2007) pp. 947-948. 
Ilustra lo anterior, entre otros casos, la situación que surge con la aplicación del art. 490 del Código Penal, que sanciona como cuasidelito al "que por imprudencia temeraria ejecutara un hecho que, si mediara malicia, constituiría un crimen o un simple delito contra las personas (...)". Tal elemento subjetivo del tipo podría no tenerse por acreditado para efectos de la responsabilidad penal, pero sí en el ámbito de la responsabilidad civil, cuya exigencia en la culpa es de menor entidad a la del tipo penal referido. Como lo puntualiza Gómez Orbaneja, "podría ser que ambos ordenamientos jurídicos, para deducir consecuencias jurídicas diversas de un mismo acaecimiento, partiesen, hasta un cierto punto, de conceptos comunes e indiferenciados, en virtud de los cuales el acto humano de voluntad (y un acto humano necesita ser tanto el delito -doloso o culposo- como el hecho ilícito civil) entra en cierta categorías previas, tales que en unión de otras, hacen de ese acto un delito, y en unión de otras distintas lo convierten, independientemente, en fuente de obligaciones de derecho civil" 24 .

Por su parte, la contradicción entre resoluciones judiciales se podría explicar porque la aplicación de una sanción penal puede juzgar hechos tipificados como delito por la ley, pero sin que ello signifique, estrictamente, una resolución sobre los aspectos civiles vinculados al hecho sobre el cual recae el pronunciamiento de la sentencia penal. Así, por ejemplo, se podría sancionar a una persona por el delito previsto en el art. 470 No 4 del Código Penal, que castiga "a los que defraudaren haciendo suscribir a otro con engaño algún documento"; sin embargo, la imposición de la pena al culpable no significa que el documento utilizado para cometer el delito sea nulo. Lo anterior es consecuencia de que en nuestro sistema civil -como principio rector- la nulidad solo puede ser establecida mediante una declaración judicial (art. 1687 CC). Lo anterior se explica porque "la exclusión del delito no impone el reconocimiento de la validez del acto. Inversamente, no siempre la declaración del delito implica la anulación del acto" ${ }^{25}$.

En nuestro proceso penal, para solucionar el problema referido, en más de una ocasión se ha optado por buscar soluciones a las víctimas de delitos, sin necesidad de declarar la nulidad, por evidentes razones de justicia ${ }^{26}$.

Por último, también es posible que el legislador limite la declaración del derecho a un determinado ámbito, sin reconocer a la sentencia una proyección prejudicial. Esta técnica

${ }_{24}$ Gómez (2009) p. 229.

25 Gómez (1947) T. I, pp. 187. En nuestra jurisprudencia aceptan este criterio, entre otras, Odde Reyesm, Emma con Ramírez Inostroza, Bartolomé y otro (2009) (se rechazó la demanda civil, no obstante haber condena penal por estafa).

${ }^{26}$ En tal sentido, Contra Exequiel Elgueta con Cárcamo, Pedro Antonio Elgueta Cárcamo, Cristián Nelson Cisternas Aguirre (2013). En esta causa se declaró que aunque se trataba de contratos que fueron celebrados para la ejecución de un delito, y por ende, adolecerían de causa ilícita, cuya sanción es la nulidad absoluta, "atendido el largo tiempo de tramitación del proceso, la invalidación y posibilidad de perseguir la restitución de las propiedades hipotecadas y más tarde embargadas y subastadas debe limitarse solo hasta aquellas que se encuentran actualmente en proceso de ejecución y a las que fueron adjudicadas a la misma empresa o sus personeros acusados que aún dispongan de posesión inscrita; pero no procederá contra terceros adquirentes que hayan comprado en pública subasta, respecto de quienes tampoco es posible actuar de acuerdo a las limitaciones impuestas por el artículo 10 del Código de Procedimiento Penal. En tal evento, cuando no sea posible obtener la restitución de la propiedad, la acción de nulidad del contrato de hipoteca se resolverá por la de indemnizar los perjuicios (Considerando $26^{\circ}$ de la sentencia de reemplazo)". 
ha sido aceptada por la Ley $N^{\circ} 20.780$, de 29 de septiembre de 2014, sobre Reforma Tributaria al incorporar normas contra la elusión. En esos preceptos se admite expresamente que se pueda realizar una declaración de simulación "para el solo efecto tributario", sin que ello afecte la validez de los actos y contratos cuestionados por el Servicio de Impuestos Internos ante los Tribunales Tributarios y Aduaneros ${ }^{27}$. En rigor, en este tipo de situaciones de lo que se trata es obtener una declaración judicial acerca de la comisión de ciertos ilícitos, como, el fraude, el abuso del derecho o de la personalidad jurídica, situaciones que se pueden generar a partir de la existencia de actos que para otros efectos jurídicos son válidos ${ }^{28}$.

\section{PROYECCIONES DE LA PREJUDICIALIDAD}

En nuestro proceso civil la relación de prejudicialidad se aprecia en varias situaciones, a saber:

1a) En las denominadas "cuestiones prejudiciales", que forman parte del pronunciamiento del objeto del proceso civil o penal. Dependiendo de la regulación legal, se distinguen entre cuestiones prejudiciales absolutas o relativas, devolutivas o no devolutivas.

2a) En la denominada eficacia positiva o prejudicial de la cosa juzgada. Esta proyección impide que en un juicio posterior se decida en contradicción con la declaración del derecho que consta en una sentencia anterior -amparada por la cosa juzgada material-, siempre que lo resuelto en ese fallo constituya un antecedente lógico-jurídico para resolver la nueva acción deducida en un juicio. La cosa juzgada material alude al litigio examinado en el juicio y resuelto por una sentencia que alcanza inmutabilidad. Es la certeza más absoluta que obtiene una decisión jurisdiccional, sea que haya acogido o rechazado la acción deducida en un juicio ${ }^{29}$. "La prejudicialidad atiende

27 La Ley N N $^{\circ}$ 20.780, de 29 de septiembre de 2014, sobre "Reforma Tributaria que modifica el sistema de tributación de la Renta e introduce diversos ajustes en el sistema tributario”. En este cuerpo legal, entre otros cambios, se introducen en el Código Tributario de 1974 varios cambios. Para lo que aquí interesa, el artículo $4^{\circ}$ quáter dispone "Habrá también elusión en los actos o negocios en los que exista simulación. En estos casos, los impuestos se aplicarán a los hechos efectivamente realizados por las partes, con independencia de los actos o negocios simulados. Se entenderá que existe simulación, para efectos tributarios, cuando los actos y negocios jurídicos de que se trate disimulen la configuración del hecho gravado del impuesto o la naturaleza de los elementos constitutivos de la obligación tributaria, o su verdadero monto o data de nacimiento".

28 El tema ya ha sido discutido en nuestra jurisprudencia aunque para otros efectos, como ocurrió Constructora Grofman S.A. y otro c/ Constructora VCGP Chile S.A. y otros (2012); en materia laboral, exigiendo prueba de la intencionalidad del fraude a la ley, Palma Aravena, Soledad c/ Comercial Nueva Suiza Ltda (2011). Sobre el tema, Atienza y Ruiz Manero (2006) pp. 13-129.

29 En relación a esta distinción, la jurisprudencia ha explicitado la necesidad de utilizar este criterio de diferenciación el fallo de la Corte Suprema, de 21 de octubre de 2008, al señalar: "para dilucidar lo anterior corresponde aclarar la diferencia entre el concepto de cosa juzgada material y el de cosa juzgada formal, divergencia que resulta ser radical, por tratarse de fenómenos completamente diversos. La primera alude al litigio examinado en el juicio y resuelto por una sentencia que alcanza inmutabilidad, siendo la certeza más absoluta que obtiene una decisión jurisdiccional, sea que haya acogido o rechazado la acción deducida en un juicio. Se trata de aquellos pronunciamientos judiciales sobre el fondo, que no pueden ser revisados en procesos posteriores. En cambio, bajo la expresión de cosa juzgada formal se alude a las decisiones judiciales que son susceptibles de una revisión 
al fenómeno de la conexión de procesos cuando la decisión de uno de ellos es la base lógica-jurídica necesaria para la resolución del otro (efecto positivo de la cosa juzgada)" ${ }^{30}$. El tema está presente actualmente en la regulación del ejercicio de la acción civil proveniente de una declaración de ilicitud de un acto como contrario a la libre competencia ${ }^{31}$.

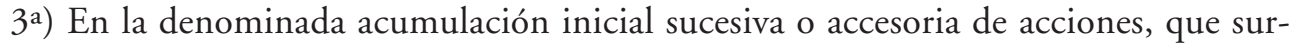
ge cuando en una demanda se han deducido dos o más acciones, entre las que existe un vínculo de tipo lógico-jurídico que determina que la resolución de la afirmada como principal incide en la o en las restantes acumuladas ${ }^{32}$; si es acogida la acción principal se puede conceder la protección jurídica solicitada a través de las acciones

posterior (...). De lo anterior se deriva necesariamente que por tratarse de una resolución que únicamente ha producido el efecto de cosa juzgada formal y no material o substancial, la sentencia interlocutoria que puso término a la causa rol No 21.138-98 no posee la naturaleza exigida por la ley para atribuirle 'autoridad de cosa juzgada'" (Comunidad Los Campos de Cano Gallegos de los Andes con Sociedad de Inversiones e Inmobiliaria Sierra del Cóndor Ltda. (2008), con referencia a la sentencia de 23 de junio de 1980). Con anterioridad, Karl Salas, Elexis con Soza Soza Humberto (2008), al resolver: "Noveno: Que sin perjuicio de lo señalado precedentemente y solo a mayor abundamiento, resulta oportuno subrayar que la sentencia interlocutoria que puso término a la causa rol No 13.968 no posee la naturaleza exigida por la ley para atribuirle 'autoridad de cosa juzgada', por tratarse de una resolución que únicamente ha producido el efecto de cosa juzgada formal y no material o substancial. Aparece ilustrativo señalar al efecto, que la diferencia entre el concepto de cosa juzgada material y el de cosa juzgada formal es radical, puesto que se trata de fenómenos completamente diversos. La primera alude al litigio examinado en el juicio y resuelto por una sentencia que alcanza inmutabilidad, siendo la certeza más absoluta que obtiene una decisión jurisdiccional, sea que haya acogido o rechazado la acción deducida en un juicio. Se trata de aquellos pronunciamientos judiciales sobre el fondo, que no pueden ser revisados en procesos posteriores. En cambio, bajo la expresión de cosa juzgada formal se alude a las decisiones judiciales que son susceptibles de una revisión posterior. Al respecto esta Corte, en sentencia de 23 de junio de 1980, explica 'se entiende por cosa juzgada formal el efecto que produce una sentencia definitiva o interlocutoria firme, en cuanto no puede ser objeto de recurso alguno, pero admite la posibilidad de modificarse lo resuelto en un procedimiento posterior. La sentencia es inimpugnable, pero es mutable mediante sentencia dictada en un juicio diverso. En cambio, la cosa juzgada material o substancial, es el efecto que produce una sentencia firme, definitiva o interlocutoria, en cuanto no puede ser objeto de recurso alguno, ni de modificación en el mismo juicio ni en un procedimiento diverso' (Revista de Derecho y Jurisprudencia, tomo 77, sección primera, página 49)”. Otras sentencias que aceptan la distinción entre cosa juzgada formal y material, Sindicato de Trabajadores Catedral (2005).

30 Vallespín (2007) pp. 23-24.

31 En nuestra jurisprudencia, esta manifestación se aprecia en la sentencia de la C. de Ap. de Santiago, de 8 de noviembre de 2011, al señalar: “ $14^{\circ}$ ) Que previo a determinar la existencia o no de los perjuicios cobrados, es dable anotar que la acción intentada tiene por causa la conducta anticompetitiva sancionada previamente. En lo sustancial el ilícito monopólico que lesiona efectivamente la libre competencia es independiente del daño civilmente compensable, puesto que no necesariamente un ilícito monopólico coexiste con un ilícito civil. (Domingo Valdés Prieto, 'Libre Competencia y Monopolio', Editorial Jurídica de Chile, 2.010, pag. 278). El injusto civil, propio de esta acción, no es otro que el derivado de la ofensa monopólica, siempre que el daño sea cuantificable pecuniariamente y que la víctima del mismo sea determinable, lo que no ocurre en un ilícito monopólico que solo atenta contra el orden público económico, generando un perjuicio social, no asimilable o difuso a nivel individual o de un agente comercial específico. En el caso de autos, de conformidad al artículo 30 del DL 211, la sentencia del Tribunal de Libre Competencia es un presupuesto formal para efectos de iniciar el juicio indemnizatorio y por ello se verifica la denominada 'función positiva o prejudicial de la cosa juzgada', esto es, cuando por expresa disposición del legislador una resolución firme o ejecutoriada debe servir de base a lo que corresponde decidir a otros tribunales en procesos posteriores" Philip Morris Chile con Empresas CCT S.A. (2011). Mayores antecedetes cfr. Romero (2012) pp. 93-102.

32 Cfr. Aragoneses (1995) T. III, p. 4998. 
acumuladas en forma sucesiva o accesoria, como ocurre con el ejercicio conjunto de la acción de nulidad de un acto y contrato y la reivindicatoria intentada contra el actual tercero poseedor, conforme a lo previsto en el art. 1689 del Código Civil ${ }^{33}$.

$4^{a}$ ) En la reglamentación de la acumulación sobrevenida por reunión, que surge cuando los procesos ya pendientes para su composición se funden en uno solo, siendo su manifestación más típica la acumulación de autos (art. 92 CPC).

5a) En la denominada prejudicialidad en la acción, que tiene lugar en los casos donde la iniciación de un determinado proceso está subordinada a una declaración judicial anterior ${ }^{34}$. Esta relación se presenta, a modo ilustrativo, en la petición de exequátur para poder hacer cumplir una sentencia extranjera. La naturaleza de cuestión prejudicial proviene del hecho que sin contar con esa autorización de la Corte Suprema, la sentencia extranjera no puede ser reconocida como título ejecutivo, quedando privada de eficacia para pedir su cumplimiento en nuestro país ${ }^{35}$.

6a) En la reglamentación del recurso de revisión de una sentencia firme, en cuanto exige la declaración judicial previa de ilicitud de la prueba que sirvió de base al pro-

33 Ha admitido la necesidad de considerar la relación de prejudicialidad en el ejercicio de la acción restitutoria, la sentencia de la CS, de 25 de mayo de 2011, señalando: "DECIMOTERCERO: Que, entonces lo que echa de menos el sentenciador de la instancia es un presupuesto esencial de procesabilidad para hacer valer la pretendida por el actor, el que, por lo mismo, no pudo obviarse para el éxito de la acción impetrada. En efecto, ha debido dirigirse la acción de nulidad en contra de todas aquellas personas que celebraron contratos que derivaron en aquel que confirió la posesión al demandado de reivindicación, puesto que la ineficacia declarada de la convención primitiva de julio de 1999, no puede afectar a las posteriores que se mantienen plenamente vigentes en la medida que respecto de estas nada se ha dicho, puesto que ningún efecto puede atribuirse a la sentencia respecto de ellas, en atención a que quien intervino en las mismas -Jaime Aceval González- no fue llamado a juicio a exponer lo conveniente a sus derechos. Se trata de un tercero ajeno al contrato nulo, pero que deriva derechos de él, y que por ende, no puede verse afectado por la declaración requerida (...); DECIMOCUARTO: Que, de la forma reseñada no puede entonces sostenerse que no es necesario dirigir la acción de nulidad tanto en contra de los que celebraron el contrato como de aquellos que derivan derechos del mismo o de otras convenciones posteriores cuando se entabla la acción reivindicatoria en contra de los actuales poseedores, como consecuencia de esa nulidad, puesto que, como se dijo, los derechos de los terceros se verían menguados si se les excluye del juicio de nulidad, en la medida que si bien se busca reponer el dominio en la persona que, de no mediar el acto reconocido como nulo no la habría perdido, ello no autoriza para prescindir de la declaración de nulidad de todos los actos anteriores o posteriores con los afectados o legítimos contradictores, ya que la reivindicación, es consecuencia de la declaración de la nulidad. De forma tal, que los efectos de la acción de dominio en vinculación con la nulidad, destinados a retrotraer las cosas al estado anterior al acto nulo, no es procedente sean oponibles respecto de quien no compareció al juicio a defenderse, y a quien de sostenerse lo contrario, afectaría una sentencia emitida en un juicio en que no fue emplazado, contrariando lo dispuesto en el artículo $3^{\circ}$ del Código Civil (...). DECIMOQUINTO: Que así las cosas, resulta elocuente que en el caso sub lite pudo darse lo que en doctrina se denomina litis consorcio necesario o acumulación subjetiva, es decir, la concurrencia de pluralidad de partes, en este caso pasiva, que conforme a la naturaleza de la relación jurídica, determina que el asunto controvertido debe ser resuelto a través de una decisión única por el juez y que resulta imprescindible en un proceso impuesto por el carácter único e indivisible que la relación sustantiva impone. La necesidad de proceder de la forma expuesta, como ya se adelantó, se debe a los efectos perjudiciales que la cosa juzgada acarrea a los derechos del omitido" Letelier Pimentel, Orlando con Pimentel Pérez, Orlando e Inmobiliaria e Inversiones G.y A. S.A. (2011).

34 Gómez (1947) T. I, p. 133.

35 Entre otras, la naturaleza de cuestión prejudicial del exequátur está reconocida, entre otras, en las siguientes sentencias de la Corte Suprema: Moyano, Francisca con Hernández Pizarro, Hernán (2008); Gold Nutrition Industria y Comercio (2008); Yarur Terre, María con Bois Courtade, Denis (2009); Quisheng Resources con Minera Santa Fe (2014). 
nunciamiento de la sentencia que se solicita rever por alguna de las partes, invocando alguna de las causales del artículo 810 Nos. 1, 2 y 3 del Código de Procedimiento Civil. La sentencia que hace esta declaración prejudicial, según la jurisprudencia, puede ser civil o penal ${ }^{36}$.

7a) En la litispendencia impropia, que surge en el caso de juicios tramitados paralelamente y que no es factible acumular, en los términos que más adelante se explican.

$8^{a}$ ) En la protección del derecho que se puede intentar preliminarmente a través de las medidas prejudiciales precautorias, probatorias y preparatorias. En estos casos se alude a proyecciones diversas de las que conforman la prejudicialidad en sentido técnico.

Como se puede apreciar del cuadro anterior, la prejudicialidad está presente en una variedad de instituciones procesales. En lo que sigue el examen del tema se centrará preferentemente en las cuestiones prejudiciales en sentido técnico.

\section{LA SOLUCIÓN SURGIDA EN NUESTRA CODIFICACIÓN}

\section{A) EXPLICACIÓN GENERAL}

El actual régimen general de la prejudicialidad es una herencia de la codificación del siglo XIX, cuya incorporación se debe a los códigos de Procedimiento Civil de 1902 y de Procedimiento Penal de 1906.

El modelo chileno tiene como originalidad el haberse separado de la propuesta seguida en otros códigos, que tomaron como piedra angular la regla atribuida al jurista francés Merlin, en virtud de la cual "lo criminal domina o paraliza a lo civil" (le criminal tient le civil en état $)^{37}$.

\footnotetext{
36 Sáez Carrasco, Pilar (1982), al declarar, "10) Que para que proceda la revisión de una sentencia dictada en un procedimiento civil, entre partes, que se ha fundado en documentos falsos es necesario, conforme a lo dispuesto en el artículo 810 No 1 del Código de Procedimiento Civil, que esa falsedad haya sido declarada por sentencia ejecutoriada, dictada con posterioridad a la sentencia que se trata de rever; condiciones que se cumplen en el caso sub lite; $2^{\circ}$ ) Que, conforme a este precepto, no es requisito que la falsedad emane de la comisión de un delito y que, como consecuencia, ella deba establecerse en un juicio criminal, sino que basta con que se trate de la afirmación de un hecho positivo o negativo, contrario a la verdad o autenticidad, proveniente de error, ignorancia o cualquier otra causa, aunque no exista culpa o dolo de parte del agente. En efecto, la ley no distingue en este acápite acerca del origen de la falsedad, lo que impide discriminar entre la naturaleza, civil o criminal, de la sentencia que la declara, sino que en el número que se sigue, que contempla otro caso de revisión, el de la sentencia dictada con el único fundamento del falso testimonio de testigos, exige expresamente que dichos testigos hayan sido condenados por el delito consiguiente; es decir, conforme a un buen razonamiento jurídico debe concluirse que si, en un caso, la ley exige el previo ejercicio de la acción penal y la condena del reo, mientras en el otro guarda silencio, es porque en este último se satisface con la sentencia declarativa ejecutoriada".

37 Esa regla fue recogida en la codificación gala en el art. 3 del Código de Instrucción criminal francés y seguida por otros sistemas de enjuiciamiento que lo siguieron como fuente de inspiración [Cfr. MARTínez (1910) pp. 22-23]. Algunos postulan que el origen de esta solución ya estaba en el derecho romano. Como lo explica RoBLES REYES, partiendo de la distinción entre iudicia publica y iudicia privata, las resoluciones penales tendrían preferencia respecto de las civiles. La preferencia absoluta del juicio penal sobre el civil fue el criterio general y lógico, que sigue observado en el derecho actual. Sin embargo, en los textos jurídicos romanos las soluciones son variadas y, en algún caso, abiertamente contradictorias [Robles (2003) pp. 20-23]. Para entender la proyección de esta regla en los sistemas que lo siguieron, a modo de referencia, en el Código Civil argentino el artícu-
} 
La propuesta francesa llevó a reconocer, como principio rector del tema, que la judicatura penal adquiriera prevalencia sobre la judicatura civil, en relación al juzgamiento de hechos con elementos comunes. Las razones invocadas para sustentar esta opción de coordinación en la actuación entre jueces supone que el interés en la represión se antepone al de la reparación civil, por un lado, y en el pretendido mayor rigor en el establecimiento del hecho que se garantizaría en el pronunciamiento de la sentencia penal ${ }^{38}$.

En cuanto al sistema seguido, el régimen general de prejudicialidad proviene de las opciones incorporadas por nuestro legislador en las normas sobre la distribución de competencia entre los distintos jueces de igual jerarquía y en la regulación de los efectos de la cosa juzgada, en los términos que pasamos a explicar ${ }^{39}$.

Con el objeto de distribuir el trabajo entre los jueces con competencia civil y penal, el legislador reglamentó las denominadas “cuestiones prejudiciales civiles y penales”. La Ley de Organización y Atribuciones de los Tribunales, de 1875, no se ocupó de esta materia, dejando la solución del problema a lo que se dispondría en el Código de Procedimiento Penal (CPP). En efecto, en el Mensaje con el que el presidente Jorge Montt envió al Congreso Nacional ese cuerpo legal, el 31 de diciembre de 1894, indicaba que, "ha sido reglamentado minuciosamente el ejercicio de las acciones que nacen del delito, la influencia mutua de las acciones civiles y criminal y los casos y forma en que es indispensable ventilar previamente a la acción criminal la civil prejudicial". La propuesta anterior se plasmó en los arts. 20 y 21 del referido CPP, promulgado el 12 de junio de 1906. Con posterioridad, la Ley $\mathrm{N}^{\circ}$ 7.421, de 9 de julio de 1943, dispuso que esas normas se trasladaran al Código Orgánico de Tribunales, incorporando como nuevo título el relativo a las "reglas sobre competencia civil de los tribunales en lo criminal" (arts. 171 a 174) ${ }^{40}$.

En lo que respecta a la competencia, se optó por configurar un modelo mixto o ecléctico, al reconocer competencia al juez penal para resolver las cuestiones prejudiciales civiles que pudieran presentarse en la decisión de los asuntos penales, salvo que se tratase de alguna de las delimitadas como cuestiones prejudiciales civiles absolutas y devolutivas.

lo 1.101 dispone: "si la acción criminal hubiere precedido a la acción civil, o fuere intentada pendiente esta, no habrá condenación en el juicio civil antes de la condenación del acusado en el juicio criminal, con excepción de los casos siguientes: $1^{\circ}$ Si hubiere fallecido el acusado antes de ser juzgada la acción criminal, en cuyo caso la acción civil puede ser intentada o continuada contra los respectivos herederos; $2^{\circ}$ En caso de ausencia del acusado, en que la acción criminal no puede ser intentada o continuada”.

38 Entre otros, una síntesis, cfr. Peyrano (2010) p. 93; Pérez (1982) 42-43. Otros antecedentes sobre el tema, cfr. GonZÁlez (2002) pp. 39-40.

39 En la doctrna clásica, esta forma de abordar el tema ha sido descrita por CHIOVENDA, con las siguientes razones, “(..) dada la necesidad de distribución de la competencia entre jueces diferentes, por la cual todo juez puede tenerla para resolver preliminarmente una cuestión que, tomada separadamente, sería competencia de otro juez, y dada la misma relación que hay entre cosa juzgada y competencia, por la cual toda decisión con autoridad de cosa juzgada debe proceder del juez competente, veríamos un continuo suspender pleitos para remitirlos de uno a otro magistrado, si sobre cada punto preliminar discutido el juez debiere pronunciar con autoridad de cosa juzgada. De ahí la necesidad de mantener la cosa juzgada dentro de los límites de la demanda, y de distinguir en el conocimiento de las cuestiones prejudiciales o motivos sobre los cuales el juez deba pronunciar incidenter tantum, esto es, al solo efecto de preparar el pronunciamiento, aunque per se no entren en su competencia; y la demanda, a base de la cual el pleito viene asignado a su competencia, y sobre la que provee principaliter, con autoridad de cosa juzgada" [Chiovenda (1977) t. II, p. 731]. 40 Una síntesis con la historia de la discusión de los arts. 20 y 21 [actuales 173 y 174 COT] en LAzo (1917) pp. 54-61. 
En este último caso, ellas debían ser enviadas a un juez civil o al órgano administrativo -en el caso de las cuentas fiscales-, para su resolución, paralizando mientras tanto la tramitación de la causa penal.

En relación al vínculo entre la prejudicialidad y la cosa juzgada, el tema se abordó fundamentalmente en el Código de Procedimiento Civil, en un conjunto de preceptos cuyo alcance general pasamos a examinar.

\section{B) LAS INFLUENCIAS DE LA COSA JUZGADA CRIMINAL EN EL PROCESO CIVIL}

Las relaciones entre la jurisdicción civil y penal, con especial nexo en la cosa juzgada, ha sido una temática muy debatida en distintos periodos históricos. Este hecho explica la diversidad de soluciones propuestas y contempladas a nivel legal en diversos países sobre el particular ${ }^{41}$. En nuestro medio, por influencia de la doctrina francesa, este asunto ha sido conocido, por décadas, como "las influencias de la cosa juzgada" 42.

En nuestro sistema el régimen general se contiene en los artículos 178, 179 y 180 del CPC; en esos preceptos el legislador intenta delimitar los efectos que se debe reconocer a una sentencia, diferenciando si se trata de un fallo condenatorio o absolutorio dictado en sede penal o civil. En palabras de Martínez, que es uno de los primeros comentaristas de este tema en nuestro medio, "para que la cosa juzgada en lo criminal produzca sus efectos en lo civil, es preciso que el hecho que sirve de base a la acción civil sea idénticamente el mismo que ha sido propuesto y probado en lo criminal por una declaración de culpabilidad" 43 .

En lo medular, la solución anterior sería seguida luego por el Código Procesal Penal (aprobado por la Ley $\mathrm{N}^{\circ}$ 19.696, de 12 de octubre de 2000), en las reglas de los artículos 59 al 68. El art. 59 inc. $3^{\circ}$ del Código Procesal Penal, dentro de la regulación de la acción civil en el proceso penal, dispone: "con la sola excepción indicada en el inciso primero [se refiere a la acción de restitución] las otras acciones encaminadas a obtener la reparación de las consecuencias civiles del hecho punible que interpusieren personas distintas de la víctima, o se dirigieren contra personas diferentes del imputado deberán plantearse ante el tribunal civil que fuere competente de acuerdo a las reglas generales”.

Sin embargo, en la introducción del modelo acusatorio se han introducido algunos cambios que han afectado el sistema de prejudicialidad. Se trata de problemas que no surgieron durante la vigencia del modelo inquisitivo, simplemente porque la competencia del

\footnotetext{
41 Como lo señalaba Mortara a fines del siglo XIX, "la recta y precisa determinación de la relación jurídica que media entre la acción penal y la acción civil, derivadas del mismo hecho, y, por consiguiente, la definición de las normas que regulan el ejercicio de la segunda en presencia de la primera, ha constituido siempre uno de los más difíciles problemas del derecho judicial” [MORTARA (1895) pp. 5-6].

42 Las relaciones entre la jurisdicción civil y penal fue una temática muy debatida en la doctrina y jurisprudencia francesa de fines del siglo XIX. Una lata explicación del problema, con las distintas teorías, se contiene en la ponencia presentada por Marcial MarTínez al Cuarto Congreso Científico ( $1^{\circ}$ Pan-Americano), realizado entre el 25 de diciembre de 1908 al 5 de enero de 1909 en Santiago, con el título "La cosa juzgada”, publicado en Ciencias Jurídicas (VV.AA.), MARTínez (1910) pp. 2-151. Una completa explicación en el último tiempo, cfr. Barros (2007) pp. 962-973.

43 Martínez (1910) p. 22.
} 
juez penal le permitía conocer ampliamente de todas las acciones civiles, con lo cual los temas de prejudicialidad estaban subsumidos en esa solución legal.

Para el tema que interesa, uno de los principales inconvenientes surge en relación a la sentencia penal condenatoria, cuando sus efectos son invocados con posterioridad en la decisión de conflictos civiles. De un modo puntual, la dificultad se produce cuando se trata de hacer valer ese fallo contra personas naturales o jurídicas que no tuvieron la calidad de intervinientes en el proceso penal. La situación anterior, entre otras hipótesis, se puede presentar en procesos seguidos por el delito de estafa, falsificación documental, cuando la declaración del derecho realizado en sede penal puede influir en la situación jurídica de terceros adquirentes de buena fe. A modo de simples interrogantes ¿puede invocarse respecto de estos terceros la sentencia condenatoria penal? ${ }^{44}$. Si el proceso penal fundado en el modelo acusatorio ha excluido a los terceros civilmente responsables de esa relación procesal, ¡es coherente que el fallo penal condenatorio pueda invocarse contra terceros en un juicios civil posterior? ${ }^{45}$.

Por su parte, también han surgido problemas en relación al alcance del art. 180 del Código de Procedimiento Civil; este precepto señala que, "siempre que la sentencia criminal produzca cosa juzgada en juicio civil, no será lícito en este tomar en consideración pruebas o alegaciones incompatibles con lo resuelto en dicha sentencia o con los hechos que le sirvan de necesario fundamento". A través de esa fórmula, la ley pretende que lo establecido en el ámbito jurisdiccional penal no sea negado en el ámbito competencial civil, si ha dado por establecido el hecho punible, entre las partes.

No obstante lo anterior, la redacción del art. 180 referido, es criticable, atendido que actualmente no resulta exacto sostener que la sentencia penal pueda producir cosa juzgada en el ámbito civil. Para justificar lo anterior, aunque sea en una explicación general, el proceso penal tiene como función aplicar una pena a un hecho tipificado como delito, pero conciliando el interés punitivo con las salidas alternativas a la sanción penal; en cambio, el proceso civil cumple diversos fines, con la consecuencia que la cosa juzgada que se puede alcanzar en uno u otro son radicalmente diversas ${ }^{46}$.

En palabras de Carreras Llansana, es incorrecto decir que una sentencia civil pueda fundarse en la existencia de un delito, puesto que la calificación jurídico penal de un hecho nada tiene que ver con la calificación civil, de modo que, en rigor, una sentencia civil no puede depender en cuanto a su contenido de que los hechos subsumidos en la norma civil sean o no constitutivos de delito” ${ }^{7}$. En similar orientación, Gómez Orbaneja apunta que “(...) la

\footnotetext{
44 También ha surgido otro problema de carecer procedimental, en relación a estos terceros. La Ley No 20.192, de 26 de junio de 2007 incorporó como hipótesis de aplicación obligatoria del juicio sumario del artículo 680 del Código de Procedimiento Civil, la siguiente: "10) A los juicios en que se deduzcan las acciones civiles derivadas de un delito o cuasidelito, de conformidad con lo dispuesto en el artículo 59 del Código Procesal Penal y siempre que exista sentencia penal condenatoria ejecutoriada". Surge la duda si es razonable aplicar a estos terceros civiles, que no fueron intervinientes de un proceso penal, un juicio concentrado donde se les pretende hacer efectivo hechos establecidos en una sentencia penal respecto de la cual no tuvieron posibilidad de defenderse.

45 Sobre el tema, con la sintesis de la doctrina cfr. Rojas (2013) pp. 353-374; Carocca (2008) pp. 803-822.

46 Esto no obsta a la convergencia que gradualmente han llevado a una "privatización" del proceso penal. Un estudio del tema cfr. Cachón Cadenas (2013) pp. 11-33; Armenta (2013) pp. 227-254.

47 Cfr. Carreras (1962) pp. 767; en igual sentido, González (2002) cit. pp. 60-61.
} 
pretensión civil, cuyo contenido puede ser sumamente diverso (puede tratarse de una acción civil por causa ilícita, por dolo, violencia, etc., de destitución, de rescisión, de alimentos, de divorcio, de revisión de sentencia firme, etc.), no se basa en el delito, sino en el hecho que lo constituye, cuando ese hecho lesione derechos subjetivos privados. Puede basarse además, como circunstancia del delito, o como condición de penalidad; o servirse de un medio de prueba cuya confección o producción implique un delito (p. ej., documento falso...)”48.

En nuestra jurisprudencia lo anterior ha tenido acogida, al diferenciar la Corte Suprema entre la cosa juzgada y lo que denomina respecto de terceros "la eficacia del fallo" ${ }^{4}$.

En el otro extremo, que la sentencia civil no produzca efecto en el ámbito penal se debe a la opción legislativa por evitar que en la decisión del proceso penal pueda influir cualquier prejuzgamiento ${ }^{50}$.

\section{CUESTIONES PREJUDICIALES DEVOLUTIVAS Y NO DEVOLUTIVAS}

Según a quien se encomienda su resolución, se distingue entre cuestiones prejudiciales devolutivas y no devolutivas ${ }^{51}$.

En las devolutivas, la ley encomienda a un juez diverso del que conoce el objeto del proceso la solución del asunto prejudicial. En la vía no devolutiva, en cambio, se reconoce al propio juez la competencia para resolver la cuestión prejudicial, como un elemento más del pronunciamiento sobre el fondo.

El Código Orgánico de Tribunales admite, como regla general, que cada juez que actúa dentro de su competencia penal se pronuncie sobre las cuestiones prejudiciales que se

48 Gómez (2009) pp. 227.

49 La Corte Suprema ha abordado este problema en la sentencia Cayupi Cuevas, Carlai con Luengo Salvo, Zodemir y otra (2008) haciendo una distinción entre el efecto de cosa juzgada y lo que denomina "eficacia del fallo". Concretamente, allí se resolvió: $1^{\circ}$ ) Que en cuanto a los efectos de la sentencia dictada contra uno de los deudores en contra de los que no han intervenido en el juicio, la mayoría de los autores se pronuncian por la afirmativa en el sentido que se producen los efectos de cosa juzgada, aplicando la doctrina del mandato tácito, y sin perjuicio de las excepciones personales que puedan oponerse. (Manuel Somarriva, Tratado de las Cauciones. No 55. Edición 1981). Ello tiene clara aplicación en sede contractual, donde se produce el denominado 'efecto reflejo', o indirecto, y no podría discutirse sino las excepciones personales. 12º) Que no ocurre lo mismo en materia extracontractual, en que la solidaridad deriva de la ley o del hecho de ser los deudores solidarios autores comunes del hecho ilícito, pues están obligados solo 'in solidum'; por tanto, nunca se producirá la identidad legal de parte que exige la ley para que surta efecto la autoridad de cosa juzgada. Al respecto debe distinguir la eficacia del fallo y la autoridad de cosa juzgada. Por tratarse la obligación 'in solidum' de una relación jurídica de sujeto múltiple, lo decidido respecto de unos va a alcanzar a los otros, no ya como cosa juzgada sino por eficacia del fallo. Entonces la sentencia afecta tanto al acreedor o codeudor que intervino en el juicio como a los demás, con la diferencia que respecto del que fue parte concurre la cosa juzgada y la eficacia del fallo, siendo entonces lo decidido irrevocable a su respecto, mientras que para los que no fueron emplazados en el juicio va a operar solo la eficacia del fallo, y para ellos lo decidido en lo civil no revestirá el carácter de irrevocable y podrán en consecuencia discutir la decisión si experimentan un perjuicio jurídico proveniente de ella, pues en estos casos la discusión del quantum de la indemnización, que puede abarcar incluso aspectos vinculados al daño moral, es perfectamente posible" (Cayupi Cuevas, Carla cl Luengo Salvo, Zodemir y otra).

50 En este sentido, cfr. GÓMEz (2009) p. 231. En todo caso el tema no es pacífico en la doctrina; una síntesis del problema, cfr. Nieva (2010) pp. 35-40.

51 Esta distinción surge de los arts. 173 y 174 COT y 167 del CPC y 171 del CPP. 
susciten en relación al tema que debe resolver ${ }^{52}$. Para tal efecto, el art. 173 inc. $1^{\circ}$ del COT dispuso, "si en el juicio criminal se suscita cuestión sobre un hecho de carácter civil que sea uno de los elementos que la ley penal estime para definir el delito que se persigue, o para agravar o disminuir la pena, o para no estimar culpable al autor, el tribunal con competencia en lo criminal se pronunciará sobre tal hecho”.

La solución anterior descansa en el principio de la unidad conceptual de la jurisdicción, en virtud del cual, todo juez está autorizado para pronunciarse sobre aquellas cuestiones que conforman un antecedente lógico-jurídico del objeto del proceso, sin necesidad de hacer una remisión (o devolución) a otro juez o tribunal. A modo de ejemplo, se trata de hechos de carácter civil que normalmente se presentan en causas penales donde el delito investigado tiene componentes que están definidos por el derecho civil, como acontece con el parricidio del cónyuge (art. 390 CP); también para la eventual aplicación de la excusa legal absolutoria prevista en el art. 489 del Código Penal, que permite dejar de aplicar una sanción penal a los parientes allí indicados. En la doctrina clásica, lo anterior se puede explicar en palabras de Aguilera de Paz, señalando que "hay casos en que no se puede resolver sobre la responsabilidad del acusado sin sentar previamente un prejuicio acerca de alguna cuestión civil íntimamente relacionada con la criminal que es objeto de la causa" ${ }^{53}$.

\section{A) Cuestiones prejudiciales absolutas y relativas}

Según el grado de obligatoriedad o discrecionalidad en la competencia asignada al mismo juez u otro que debe pronunciarse, las cuestiones prejudiciales pueden ser relativas o absolutas. Este criterio está admitido explícitamente como un instrumento para la racionalización en la actividad jurisdiccional del proceso civil y penal.

En nuestro proceso civil la regla general en este tema es atribuir a las cuestiones prejudiciales el carácter de relativas, permitiendo que el mismo juez que conoce del objeto del proceso donde ella surja las resuelva como parte integrante de su competencia (arts. 111, 173, 174 COT y 167 CPC).

Explicado de otra forma, en la prejudicialidad relativa la ley autoriza al juez a resolverlas sin necesidad de remitir el asunto a otro juez o tribunal, aunque esto último se podría hacer bajo ciertos supuestos. Si tal reenvío no se produce, no se configura una vulneración al derecho a ser juzgado por el juez natural.

Cuando se trata de una cuestión prejudicial absoluta, en cambio, la ley obliga a remitir su decisión a otro juez competente. En este caso, técnicamente se está frente a una norma de atribución de competencia por razón de la materia, en virtud de la cual, lo fallado por el juez natural sobre la cuestión prejudicial absoluta actúa como un elemento lógico-jurídico en la decisión de otro juicio una producido el efecto de cosa juzgada ${ }^{54}$.

\footnotetext{
52 Se sostiene que la solución se remonta al origen de la facultad concedida a la jurisdicción en el derecho romano: D. 2, 1, 2 Javoleno: Cui iurisdictio data est, ea quoque concessa esse videntur, sine quibus iurisdictio explicari non potuit (A quien se le dio jurisdicción, se considera que se le concedieron también aquellas cosas, sin las cuales no pudo ejercerse la jurisdicción). Sobre el tema y el origen de esta regla GuerRa (2011).

53 Aguilera (1917) p. 63.

54 Sobre esta naturaleza se ha pronunciado la sentencia de la C. de Ap. de San Miguel, 19 de noviembre de 1991, declarando: "16. La Jurisprudencia ha declarado la incompetencia del tribunal que se pronuncia sobre el
} 


\section{B) CONSECUENCIAS PRÁCTICAS DEL MODELO ADMITIDO}

$\mathrm{Al}$ no reconocer al juez penal una competencia prevalente sobre la civil, por la vía de imponer el agotamiento de la vía criminal para juzgar una acción civil, nuestro sistema permite tramitar paralela y simultáneamente un proceso penal y otro civil, aunque conozcan de hechos comunes.

Como se ha explicado, la excepción a la regla general anterior proviene de los casos donde se puede suspender la tramitación de un proceso, en espera de la resolución de una cuestión prejudicial absoluta surgida en la causa penal, o cuando corresponde decretar la suspensión del juicio civil en curso, si se cumplen las condiciones del artículo 167 del Código de Procedimiento Civil, a saber ${ }^{55}$.

1a) Que la cuestión prejudicial penal constituya un elemento lógico y jurídico, cuya resolución es imprescindible para la decisión del objeto del proceso civil. En la nomenclatura legal, esta situación surge "cuando la existencia de un delito haya de ser fundamento preciso de una sentencia civil o tenga en ella influencia notoria"; y,

2a) Que en el proceso penal se haya realizado en contra del imputado un acto formal de imputación mediante una acusación o requerimiento ${ }^{56}$.

La solución antes descrita, resulta coherente con la separación existente entre la responsabilidad civil y la responsabilidad penal en nuestro ordenamiento.

Por su parte, estos rasgos del sistema mixto de prejudicialidad aceptado para coordinar la actuación del proceso civil y penal han sido profundizados por el Código Procesal Penal, específicamente, en el régimen de ejercicio asignado a la acción civil ${ }^{57}$. En primer lugar,

fondo de la causa, antes de que sea resuelta la cuestión prejudicial por el Tribunal a quien la ley tiene encomendado su fallo. (C. Suprema, 13.05.1932. J. al D. 1932, pág. 287)". "Carecen de competencia para continuar el juzgamiento criminal tanto el juez del proceso como el Tribunal de Alzada correspondiente que se desentienden de una cuestión previa de carácter civil, y sin que esta hubiera sido discutida en autos, prosiguen conociendo de la causa, el primero, dando lugar al sobreseimiento temporal, por no resultar totalmente justificada la perpetración del delito investigado; y este último decretando el sobreseimiento definitivo, por no ser el hecho constitutivo de delito, todo ello en circunstancias de que el juzgamiento debió paralizarse hasta que fuera fallada la cuestión civil en referencia" (C. Suprema, 26.03.1945, G. 1945, 1er. semestre, No 21, pág. 129)" Contra Vásquez Orellana, Eliana de Jesús (1991).

$55 \mathrm{El}$ art. 167 del CPC dispone para tal efecto que "cuando la existencia de un delito haya de ser fundamento preciso de una sentencia civil o tenga en ella influencia notoria, podrán los tribunales suspender el pronunciamiento de esta hasta la terminación del proceso criminal, si en este se ha deducido acusación o formado requerimiento, según el caso". "Esta suspensión podrá decretarse en cualquier estado del juicio, una vez que se haga constar la circunstancia mencionada en el inciso precedente". "Si en el caso de los dos incisos anteriores se forma incidente, se tramitará en pieza separada sin paralizar la marcha del juicio". Sobre la historia del art. 174 del CPC [actual art. 167] cfr. LAzo (1922) p. 153. Según MarTínez, el origen del art. 174 (actual 167 del CPC), habría sido tomado del Código de procedimiento penal de Holanda [MARTínez (1910) p. 146].

${ }^{56}$ La norma original del CPC contemplaba que la causa pasara a plenario, que era el juicio en el proceso penal inquisitivo (art. 76 inc. $2^{\circ}$ del Código de Procedimiento Penal). Dicha etapa comenzaba con el auto de acusación fiscal. Con la implementación del proceso penal acusatorio, la Ley 19.806, de 31 de mayo de 2002, se exige que se haya formulado a un imputado la acusación o formado requerimiento. La acusación es el acto a través del cual se deduce la acción penal por el Ministerio Público o, en su caso, por el querellante (art. 259 Código Procesal Penal).

57 La evolución legislativa del tema, cfr. Cisterna (2007) pp. 23-29. 
clarificando que ella no nace del delito, tal como se desprende, de los arts. 59, 65 y 67 del Código Procesal Penal. No deja duda sobre el particular, lo señalado en el art. 67 del Código recién referido, cuando dispone, "la circunstancia de dictarse sentencia absolutoria en materia penal no impedirá que se dé lugar a la acción civil, si fuere legalmente procedente”.

A modo de ejemplo, acudamos a un caso de indignidad para suceder para ilustrar la forma como se puede dar esta separación entre el juzgamiento penal y el civil.

Como lo explica Elorriaga, la indignidad para suceder se refiere "al mérito de una persona para suceder por causa de muerte a otra. En sentido inverso la indignidad para suceder puede ser entendida como la falta de mérito de un sujeto para suceder al causante, debido a que no cumplió con los deberes que para con él tenía o porque faltó al respeto que su memoria le imponía" 58 . Para que se produzca este radical efecto sucesorio, la ley ha establecido que esta sanción debe ser declarada judicialmente (art. 974 CC).

Ahora, el sistema de prejudicialidad relativa permite que se pueda intentar una acción de indignidad hereditaria, sin necesidad de obtener una condena penal que declare la existencia del hecho de haber cometido el homicidio de la persona del difunto o haber intervenido en él. El juez civil también está llamado a pronunciarse sobre el tema cuando ha sido promovido entre legítimos contradictores.

Lo anterior no obsta a que se pueda decretar la suspensión del proceso civil, hasta que se decida penalmente sobre ese mismo hecho, si se cumplen las exigencias del art. 167 del Código de Procedimiento Civil.

\section{LAS CUESTIONES PREJUDICIALES CIVILES ABSOLUTAS Y DEVOLUTIVAS}

\section{A) LAS Hipótesis ADMITIDAS EN LA LEY}

Las cuestiones prejudiciales absolutas y devolutivas comprenden varias situaciones, siendo las más relevantes las siguientes: los asuntos sobre cuentas fiscales; las cuestiones sobre estado civil; las relativas al derecho de propiedad u otro derecho real sobre inmuebles; la discusión sobre la calidad de herederos y sobre el derecho de dominio en una partición; y, la discusión sobre la validez del matrimonio para efectos del delito de bigamia.

En lo que sigue pasamos a examinar su contenido.

$1^{\circ}$ ) Los asuntos sobre "cuentas fiscales" (art. 173 inc. $2^{\circ}$ del COT). Su competencia actualmente la detenta la Contraloría General de la República, conociendo del tema a través del juicio de cuentas ${ }^{59}$. Este procedimiento se inicia con la formulación de un reparo por la Contraloría General de la República, cuando advierte que una cuenta no ha sido dada en forma legal por el funcionario obligado a rendirla.

En su aplicación práctica, la Instrucción General del Ministerio Público, de 11 de enero de 2013, indica al fiscal a cargo de la investigación en los delitos de corrupción como debe promover esta cuestión prejudicial, naturalmente si existen los elementos fácticos y jurídicos que lo justifican. En esa normativa se precisa que esta situación podría presentarse

58 Elorriaga (2010) p. 44.

59 Sobre el tema, Hanseen (2007) pp. 17-220; Ferrada (2012) pp. 299-316. 
en los delitos comprendidos en los párrafos $5^{\circ}$ y $6^{\circ}$ del título V libro II del Código Penal, relativos a malversaciones, fraudes y exacciones ilegales, cuando surge la necesidad de realizar un juicio de cuentas ${ }^{60}$.

$2^{\circ}$ ) Las cuestiones sobre estado civil, siempre que su resolución "deba servir de antecedente necesario para el fallo de la acción penal persecutoria de los delitos de usurpación, ocultación o supresión de estado civil”. Sobre el particular, el Código Penal regula los crimenes y simples delitos contra el estado civil de las personas (arts. 353 al 357). En la práctica, esta cuestión prejudicial civil podría promoverse si el imputado invoca tener un estado civil que incida en la resolución de los delitos de suposición de parto o de usurpación de estado civil ${ }^{61}$.

$3^{\circ}$ ) Las relativas al derecho de propiedad u otro derecho real. Para esta situación el art. 174 del Código Orgánico de Tribunales reconoce su carácter de cuestión prejudicial civil absoluta y devolutiva señalando que, "cuando se opusieren excepciones de carácter civil concernientes al dominio o a otro derecho real sobre inmuebles, y ellas estuvieren revestidas de fundamento plausible y de su aceptación, por la sentencia que sobre ellas recaiga, hubiera de desaparecer el delito"62.

Esta norma actualmente se presenta como técnicamente deficiente, atendido que en la etapa de investigación del proceso penal no existe una oposición de excepciones. Lo que sí puede acontecer es que la defensa invoque la existencia de hechos vinculados a la titularidad de un derecho real que, de ser efectiva, determine la inexistencia del hecho punible; en ese evento el Ministerio Público debe proceder a recabar los antecedentes para promover

\footnotetext{
${ }^{60}$ Según el instructivo referido, "en estos casos los fiscales privilegiarán la posición de contar con antecedentes suficientes para sostener una acusación penal, configurándose los elementos necesarios del respectivo tipo penal, oponiéndose a la solicitud de sobreseimiento temporal. Por el contrario, en caso de ser estrictamente necesario para la decisión contar previamente con una liquidación de la Contraloría General de la República y se hubiere iniciado el juicio de cuentas, el fiscal del caso solicitará el sobreseimiento temporal de la causa" (Punto 9 oficio MP 039/203 de 11 de enero de 2013).

${ }_{61}$ El Ministerio Público ha precisado el alcance de estas cuestiones prejudiciales en el Instructivo No 74, de fecha 14 de agosto de 2001. En esa normativa se indica que "suponer un parto implica fingir, con la intención de alterar el estado civil, que una mujer ha dado a luz cuando en realidad no lo ha hecho. Sujeto activo puede serlo cualquiera, aunque usualmente la mujer participará en el delito"; "la sustitución de los estados civiles de dos niños distintos, siendo indiferente que cambien o no de nombre, su condición matrimonial o extramatrimonial, su sexo, que la sustitución se realice antes o después del alumbramiento y que uno de los niños esté muerto"; en la usurpación de estado civil, según el órgano de persecución, el delito se configura cuando esa cualidad personal es asumida o apropiada por otro, sea que el apropiado esté vivo muerto, "ya que en uno u otro caso puede ocupar la posición jurídica ajena y desarrollar la correspondiente actividad jurídica que le correspondería al otro". Por último, "la conducta de sustraer consiste en quitar al menor de la esfera de cuidado y dependencia en que se encuentra"; "la conducta de ocultar o exponer implica "desvincular al hijo de la propia familia (los padres) mediante su desaparición del entorno social en que dicha relación de filiación deba mostrarse a través de su abandono" (Puntos 29 y 30 Circular No 74).

${ }_{62}$ En la jurisprudencia se ha extendido este examen de eventual cuestión prejudicial civil a una alegación sobre la demarcación entre predios, para exculparse del delito, sosteniendo que se había ejecutado actos de dominio en un predio propio. Aunque no se acogió la defensa realizada por un imputado de existir una cuestión prejudicial, la Corte de Apelaciones de Concepción, en sentencia de 28 de julio de 1989, estimó como plausible examinar si esa situación podría configurar una cuestión prejudicial que liberara al imputado del hecho investigado como delito, de haber vendido más hectáreas de bosques que las que efectivamente pudo enajenar la vendedora. Contra N.N. (1989).
} 
esta cuestión prejudicial ante el juez civil competente, dentro de la obligación que tiene de garantizar la presunsión de inocencia ${ }^{63}$.

$4^{\circ}$ ) En la partición de bienes tienen el carácter de cuestión prejudicial absoluta y devolutiva la discusión sobre la calidad de herederos y sobre el derecho de dominio. En este ámbito se ha optado por un sistema devolutivo obligatorio, separando el ámbito de la competencia del juez ordinario con la del partidor. De conformidad al art. 1330 del CC, "antes de proceder a la partición, se decidirán por la justicia ordinaria las controversias sobre derechos a la sucesión por testamento o abintestato, desheredamiento, incapacidad o indignidad de los asignatarios". Por su parte, al art. 1331 del mismo cuerpo legal reconoce otra cuestión prejudicial civil, al disponer que, "las cuestiones sobre la propiedad de objetos en que alguien alegue un derecho exclusivo y que en consecuencia no deban entrar en la masa partible, serán decididas por la justicia ordinaria; y no se retardará la partición por ellas. Decididas a favor de la masa partible, se procederá como en el caso del art. 1349”. "Sin embargo, cuando recayeren sobre una parte considerable de la masa partible, podrá la partición suspenderse hasta que se decidan; si el juez, a petición de los asignatarios a quienes corresponda más de la mitad de la masa partible, lo ordenare así" ${ }^{64}$.

$\left.5^{\circ}\right)$ En relación a la validez del matrimonio para efectos del delito de bigamia. El art. 174 del Código Orgánico de Tribunales considera como una cuestión prejudicialidad civil absoluta y devolutiva, la que puede surgir en el proceso penal con ocasión del juzgamiento del delito de bigamia. Este último hecho se tipifica cuando aquel que estando válidamente casado contrae nuevo matrimonio (art. $382 \mathrm{CP}$ ). Para el tema que aquí interesa, si uno de esos matrimonios no es válido, no puede condenarse por bigamia, puesto que la infracción penal supone la validez de los matrimonios.

No obstante lo anterior, en nuestra jurisprudencia algunos fallos han soslayado esta cuestión prejudicial civil fijando como criterio de cómputo de la prescripción de la acción penal el que se aplica a los delitos instantáneos, que comienza a contarse desde la consumación del ilícito ${ }^{65}$. La solución anterior es criticable, puesto que deja al cónyuge víctima de la

63 En el Instructivo N 74 del Ministerio Público se dispone que: “34 (...)“el ministerio público solo podrá solicitar al juez de garantía el sobreseimiento temporal y este decretarlo, cuando las excepciones civiles que indica la norma aparezcan revestidas de fundamento plausible". "Además, los derechos que se invocan deben tener naturaleza civil y guardar relación con el derecho de propiedad u otro derecho real sobre inmuebles. La jurisprudencia ha señalado que la voz “inmuebles” que emplea el artículo 174 del Código Orgánico de Tribunales debe entenderse en sentido amplio, abarcando los inmuebles por naturaleza, por adherencia o por destinación. Por último, la norma exige que hubiere de desaparecer el delito en caso de que se aceptaren las excepciones por el tribunal civil”. "35. Lo usual será que las excepciones a que hace referencia el artículo 174 del Código Orgánico de Tribunales se deduzcan tratándose de un delito de usurpación, ilícito de acción penal pública. Luego, regirá lo prescrito en el inciso final del artículo 171 del Código Procesal Penal”.

64 Sobre el tema, Somarriva (2002) pp. 356-360.

65 Un ejemplo de esta doctrina se contiene en la sentencia de la Corte Suprema, de 27 de julio de 2004, al declarar que "el delito se comete con la realización de una sola y determinada acción, cuya realización tiene lugar en un preciso momento, vale decir, la época o fecha de celebración del nuevo matrimonio, por lo que en ese instante se ejecuta, consuma y agota el ilícito, sin perjuicio que el estado matrimonial se prolongue en el tiempo, situación que se origina no del hecho delictuoso, sino de la naturaleza y carácter especial del contrato matrimonial, que produce efectos permanentes en el tiempo y en tanto este no se disuelva por causas legales". La misma sentencia puntualiza que “(...) el delito en estudio es de carácter instantáneo, y por ende, se consuma y agota al momento de su perpetración, esto es, a la fecha del nuevo matrimonio, época que además determina el inició del 
bigamia en la indefensión penal. La única manera de evitar esta situación sería controlando en el Registro Civil la eventual celebración de nuevas nupcias por parte de su cónyuge, para poder actuar antes que se consume la prescripción de la acción penal, exigencia que resulta francamente imposible de cumplir.

También esta cuestión prejudicial ha dejado de ser aplicada en los casos donde el imputado por bigamia fallece o se declara su muerte presunta, atendido que con esos hechos se extingue la responsabilidad penal ${ }^{66}$. Lo anterior, sin embargo, no impide que la discusión sobre la validez del matrimonio pueda ser debatida entre los herederos del autor del delito, conforme a lo previsto en el art. 48 letra d) de la Ley de Matrimonio Civil ${ }^{67}$.

plazo de prescripción que para estos casos y por tratarse de un simple delito es de cinco años, acorde con lo dispuesto en el artículo 94 del Código Penal" (Guerra Tapia, Mario Raúls (2004). Con anterioridad, precisando el término del cómputo de la prescripción la CS, en sentencia de 7 de mayo de 1990 declaró: "Tercero: Que, para resolver acerca del recurso de casación en el fondo de que conoce esta Corte, se hace necesario estudiar la naturaleza del delito que castiga el artículo 382 del Código Penal. Con el nombre tradicional de bigamia que nuestro Código no emplea se conoce la figura a que se refiere el indicado artículo, que sanciona 'al que contrajere matrimonio estando válidamente casado'. Según lo ha determinado la doctrina, la acción misma del delito consiste en 'contraer matrimonio'. No consiste en quedar casado, por lo cual no cabe duda de que entre nosotros, al menos, la bigamia es un delito instantáneo y no permanente, o sea, que se consuma con el hecho de contraer matrimonio, punto de máxima importancia para la prescripción (Alfredo Etcheberry, Derecho Penal, tomo IV, págs. 26 y 27). Cuarto: Sentado este principio, es indudable que la prescripción de la acción penal empieza a correr desde que se contrae el segundo matrimonio, en la especie, el día 2 de agosto de 1974. De manera que a la fecha de la denuncia 18 de agosto de 1987 dicha acción ya estaba prescrita, la que debió ser declarada de oficio por el tribunal, al estar presente el reo (artículo 102 del Código Penal), pues consta en el proceso del extracto de filiación y antecedentes (fojas 39) que ella no ha sido interrumpida y que no le afecta lo dispuesto en el artículo 100, ya que habían transcurrido más de diez años, o sea, más del doble del término señalado en el artículo 94 del mismo cuerpo legal, hacían la misma declaración" (Contra Palma Ramos, José Renato (1990)).

${ }^{66}$ En este sentido, Henríquez Gavilanes, Eliseo con Rojas Müller, Liliana (2006); Salgado Muñoz, Rosa con Concha Dolz, Claudia (2009).

${ }^{67}$ También es criticable la docrina jurisprudencial que ha declarado como válidos los dos matrimonios en las discusión hereditaria surgida sobre el tema, atendido que atenta contra el carácter unitario que tiene el matrimonio en nuestro derecho, que no acepta la poligamia como forma de organización familiar. Sin embargo, la Corte Suprema, mediante una casación en el fondo de oficio, ha procedido a reconocer a ambas cónyuges sobrevivientes los derechos hereditarios que les correspondan al momento de la apertura de la sucesión, disponiendo que debían repartirse por partes iguales entre ellas. Según esta sentencia “(...) no obstante que el fenómeno había sido advertido por la doctrina, la actual Ley de Matrimonio Civil No 19.147 de 17 de mayo de 2004, en su artículo 48 letras c) y d) mantiene el mismo plazo de prescripción, sin preocuparse del problema que se presenta una vez vencido dicho término en la sucesión del bígamo, por lo que el problema en cuestión puede volver a presentarse, resultando, por ende, de interés resolver el punto. Finalmente, también puede producirse el mismo fenómeno en el caso de que declarada la nulidad de matrimonio después del fallecimiento del bígamo, para su segunda cónyuge sobreviviente el matrimonio deba ser considerado nulo putativo a la época de la apertura de la sucesión en que todavía no se había declarado ni demandado su nulidad, por lo que este cónyuge sobreviviente pueda haber estado de buena fe, y en consecuencia, a su respecto el matrimonio nulo produce los mismos efectos del válido". En el considerando Quinto de la sentencia se admite que se trata de una solución de equidad, al expresar: "Quinto: Que, en consecuencia, en esta instancia deberá determinarse cuál será la solución que deberá adoptarse entre las posibles. Una de ellas es la de repartir la porción conyugal entre las 2 personas que invisten dicha calidad, y la otra sería la de preferir a la primera de ellas. Esto último carece de toda fundamentación jurídica puesto que deja sin aplicación un precepto legal, razón por la cual no queda sino determinar que la porción del cónyuge sobreviviente deberá repartirse entre quienes tengan esa calidad vigente al momento de la apertura de la sucesión, y no la han perdido por hechos posteriores, esto es, en el caso de autos, para doña Elisa Mora Neira, y doña Blanca Santibáñez Oporto. Esta solución aparece como más conforme 
Por último, se debe considerar que al tratarse de una cuestión prejudicial absoluta y devolutiva, su omisión configura una causal de nulidad del fallo penal, si este fue pronunciado sin esperar la resolución de este tema ${ }^{68}$.

\section{B) LEGITIMACIÓN ACTIVA PARA PROMOVERLAS}

Aunque en la práctica la existencia de los hechos fundantes de una cuestión prejudicial civil es puesta de manifiesto en la investigación penal por la defensa del imputado, el legislador ha legitimado activamente al Ministerio Público para promoverla ante el juez civil competente, o ante la Contraloría General de la República, según el caso. El art. 171 inc. $3^{\circ}$ del Código Procesal Penal dispone sobre este punto, "cuando se tratare de un delito de acción pública, el ministerio público deberá promover la iniciación de la causa civil previa e intervendrá en ella hasta su término, instando por su propia conclusión"69.

Entre otras razones, la solución anterior se explica como una medida para evitar actuaciones dilatorias de la defensa penal. Si se le reconociera la legitimación, existe el riesgo que a través de la promoción de estas cuestiones se retarde la aplicación de una pena, atendido que la remisión al juez civil competente obliga a decretar el sobreseimiento temporal, conforme lo dispone el art. 252 letra a) del Código Procesal Penal.

\section{PREJUDICIALIDAD CIVIL Y LITISPENDENCIA}

Un problema de singulares características en el tema que se examina se presenta en la tramitación simultánea de procesos civiles, cuando los respectivos objetos presentan entre sí relaciones de prejudicialidad.

La situación anterior, en principio, debería tener como cauce normal decretar la acumulación de procesos, conforme a las reglas legales generales o especiales. Sin embargo, en la práctica la ley no reconoce siempre esta posibilidad. Lo anterior ocurre, por ejemplo, en procedimientos seguidos ante jueces o tribunales con competencias diversas por razón de la materia o cuando se utilizan procedimientos diferentes, pero que presentan como elemento común que se estén conociendo de acciones vinculadas prejudicialmente, generando el riesgo de emitir decisiones contradictorias sin una justificación jurídica ${ }^{70}$.

con las circunstancias de que existen 2 matrimonios que jurídicamente han de tenerse como válidos, que deben producir todos sus efectos, y entre ellos los de otorgar derechos sucesorios, sin que concurra causal alguna de exclusión para ninguna de las cónyuges sobrevivientes. Y además, está de acuerdo con la equidad, pues no se ha probado en autos mala fe para ninguno de los posibles asignatarios, en cuanto al otorgamiento de un matrimonio nulo, por cuya razón privar a cualquiera de las cónyuges sobrevivientes de derechos hereditarios sería injusto" [Pérez Mora, Rosa del Carmen con Santibáñez Oporto, Blanca Silvia y otra (2005)]”.

68 En tal sentido, Contra Mittersteiner Pig, Georgina Francisca (1994).

69 Sobre el tema, cfr. Maturana y Montero (2012) pp. 421-423.

70 La necesidad de evitar sentencias contradictorias en procesos tramitados separadamente ha sido abordado por la Corte Suprema en Fisco de Chile con Inmobiliaria Caymaco Del Pino Ltda. (2012), señalando que: "UNDÉCIMO: Que el error incurrido provocó otro de mayor significación, el de desatender la norma del artículo 92 del Código de Procedimiento Civil, que autoriza la acumulación de autos, que el mismo tribunal había considerado procedente, ya que en esta situación, decidido que se trataba de dos procesos que se tramitaban separadamente, se determinó como algo razonable e incuestionable que ambos expedientes constituían un solo juicio y que por ello debían terminar en una sola sentencia, puesto que las acciones emanaban directa e inme- 
De un modo concreto, lo anterior puede surgir, por ejemplo, cuando en juicios paralelos se han deducido pretensiones objetivamente contradictorias, como sería solicitar declarar la nulidad de un contrato en un juicio ordinario de mayor cuantía y luego, en un juicio sumario, pedir la indemnización de perjuicios, dando por válido el contrato; también si se pide la resolución del contrato y luego, en un proceso posterior y diverso, se requiere el cumplimiento forzado del mismo o se invoca este acto como un hecho fundante de la protección al consumidor; si se deduce una acción de petición de herencia y luego en un proceso de familia se impugna la filiación del supuesto heredero; si se solicita una indemnización de perjuicios invocando el derecho de patente y el demandado solicita la nulidad de la misma ante el Instituto Nacional de Propiedad Industrial (INAPI).

Como se puede advertir, los conflictos aludidos generan el riesgo objetivo que jueces o tribunales puedan dictar pronunciamientos irreconciliablemente contradictorios.

En otros ordenamientos los problemas de la tramitación de procesos paralelos -con objetos vinculados por relación de prejudicialidad-, cuando no se pueden acumular los autos, se han solucionado ampliando el ámbito de actuación de la prejudicialidad, admitiendo otras manifestaciones junto a los criterios clásicos, como la prejudicialidad civil-civil, la administrativa o la laboral ${ }^{71}$.

También este inconveniente ha sido abordado reconociendo la existencia de la excepción de litispendencia impropia o por conexión, a través de la cual se permite paralizar la tramitación del segundo proceso, por el hecho de estar pendiente de decisión un juicio

diatamente de unos mismos hechos: la expropiación de un inmueble de propiedad de la sociedad reclamante y reclamada en dichos autos, respecto del cual se fijó por la comisión de expertos un valor determinado como monto provisional de indemnización, todo con el objetivo de asegurar lo que la misma norma dispone: mantener la continencia, o unidad de la causa, lo que en el presente caso manifiestamente no se logró, puesto que los jueces del fondo incumpliendo lo señalado, resolvieron de manera separada ambos recursos, expresando en la última sentencia, que no podían dar satisfacción a reparar el agravio de la recurrente, puesto que como habían fallado ya una de las apelaciones se encontraban obligados a confirmar la segunda, para evitar sentencias contradictorias, o sea, precisamente aquello que debió hacerse con la vista conjunta y simultánea de ambos recursos. De más está señalar el error procesal cometido, de haber declarado inadmisible una apelación aduciendo un factor de inadmisibilidad inexistente que hubo de corregir más tarde, cuando dicha reparación era absolutamente inidónea, como se expresó en la misma segunda sentencia, ya que solo cabía dictar, frente a la realidad procesal, lo que era evidente, la confirmación de lo resuelto, puesto que el tribunal había decidido con anterioridad la misma cuestión debatida por el primer recurso de apelación".

${ }^{71}$ En Ley de Enjuiciamiento Civil española de 2000, junto a las clásicas cuestiones prejudiciales civiles y penales, se admite las "cuestiones prejudiciales no penales" y la "prejudicialidad civil". De un modo concreto art. 43 de la LEC señala que "cuando para resolver sobre el objeto del litigio sea necesario decidir acerca de alguna cuestión que, a su vez, constituya el objeto principal de otro proceso pendiente ante el mismo o distinto tribunal civil, si no fuere posible la acumulación de autos, el tribunal, a petición de ambas partes o de una de ellas, oída la contraria, podrá mediante auto decretar la suspensión del curso de las actuaciones, en el estado en que se hallen, hasta que finalice el proceso que tenga por objeto la cuestión prejudicial. En nuestro proceso, el art. 221 del Proyecto de Código Procesal Civil, en plena discusión, aborda el tema las "cuestiones prejudiciales no penales", disponiendo que: "siempre que, para dictar una sentencia definitiva civil, sea necesario decidir, previamente, una cuestión de carácter civil u otra regida por leyes especiales, que se esté sustanciando en juicio iniciado con anterioridad, ante el mismo tribunal o ante otro distinto, y no fuere posible la acumulación de procesos, el tribunal, a petición de ambas partes o de una de ellas, oída la contraria, podrá suspender el pronunciamiento de la sentencia, hasta que finalice el proceso en que se ventila la cuestión”. 
cuyo objeto se proyecta prejudicialmente al segundo juicio iniciado entre las mismas partes o con terceros.

La admisión de la litispendencia impropia obliga a cambiar la concepción clásica de la triple identidad, como criterio de verificación, que tradicionalmente ha discurrido en determinar la identidad entre los objetos procesales. En efecto, como se trata de hipótesis de juicios paralelos que se excluyen jurídicamente por interferir o producir el segundo juicio iniciado un prejuzgamiento, no es factible verificar la presencia de la triple identidad. No obstante lo anterior, para evitar que se puedan pronunciar decisiones jurídicamente inconciliables se acepta la litispendencia impropia, evitando la tramitación del segundo pleito, cuyo objeto es prejudicialmente inconciliable con el promovido en el primer juicio ${ }^{72}$.

El problema referido en nuestro proceso civil se puede presentar perfectamente, atendida la proliferación de procedimientos especiales y por la fragmentación de la competencia que se viene dando entre diversos jueces y tribunales, que muchas veces están llamados a conocer de temas conexos. Por lo mismo, la solución a esta situación dependerá de la forma como el legislador autoriza a oponer la excepción de litispendencia, según se trate de procesos escritos o con audiencia preparatoria.

\section{CONCLUSIONES}

10) La prejudicialidad es una institución jurídica con varias proyecciones en nuestro proceso civil, pero cuya reglamentación requiere de una actualización que supere el esquema binario de relaciones que pueden surgir solo entre proceso civil y penal.

$2^{\circ}$ ) La jurisprudencia ha reconocido un amplio campo de acción a la prejudicialidad, como una exigencia para el correcto desenvolvimiento de varias figuras relevantes en el ejercicio del derecho de acción.

\footnotetext{
72 Sobre el tema, con una síntesis de la doctrina y jurisprudencia española MálAGA (1999) pp. 551-568; CorDÓN MoReno (1996) pp. 145-159. Una síntesis de la aplicación de esta figura se encuentra, entre otras, en la sentencia de 29 de diciembre de 2011 (Sentencia núm. 942/2011) de la Sala de lo Civil, Sección $1^{a}$ del Tribunal Supremo español, al señalar: "lo expuesto fue determinante de que la jurisprudencia desarrollada bajo el sistema de la Ley de Enjuiciamiento Civil de 1881 (LEG 1881, 1) admitiese la denominada litispendencia impropia o por conexión, que, en realidad, integra un supuesto de prejudicialidad civil que tiene lugar cuando un pleito interfiere o prejuzga el resultado de otro, con la posibilidad de dos fallos contradictorios (en este sentido, sentencia 121/2011 de 25 febrero (RJ 2011, 2483) y las en ella citadas). 27. Ahora bien, como precisa la sentencia 628/2010, de 13 octubre (RJ 2010, 7451), "[l] a jurisprudencia de esta Sala ha venido a perfilar la distinción entre litispendencia y prejudicialidad civil, que hoy reconoce el artículo 43 de la Ley de Enjuiciamiento Civil (RCL 2000, 34, 962 y 2001, 1892), subrayando que lo operativo es la sujeción que, por razones de lógica y conexión legal, determinan una prejudicialidad entre el objeto de un litigio y otro, de tal alcance que vinculan el resultado del segundo al primero (sentencias de 19 de abril (RJ 2005, 3244) y 20 de diciembre de 2005 (RJ 2005, 10150)). Se trata de la llamada litispendencia impropia o prejudicialidad civil, que se produce, como ha dicho la sentencia de 22 de marzo de 2006 (RJ 2006, 2315) , cuando hay conexión entre el objeto de los dos procesos, de modo que lo que en uno de ellos se decida resulte antecedente lógico de la decisión de otro (SSTS 20 de noviembre de 2000, 31 de mayo, 1 de junio (RJ 2005, 6384) y 20 de diciembre de 2005) aun cuando no concurran todas las identidades que exigía el artículo 1252 del Código Civil (LEG 1889, 27). 28. Lógica consecuencia de la función que cumplen ambas instituciones es que pierdan de manera sobrevenida su interés cuando se resuelve el pleito anterior pendiente y dejan de cumplir la finalidad preventiva, quedando desprovistas de efecto alguno, pronunciándose en este sentido en un caso similar la sentencia 488/2007, de 3 mayo (RJ 2007, 2823)".
} 
$3^{\circ}$ ) Existen omisiones legislativas que provienen de la proliferación de tribunales especiales o de la utilización de procedimientos diversos, donde la declaración jurídica que se puede hacer tiene este vínculo de prejuzgamiento, que obliga a evitar que se pronuncien sentencias contradictorias que no puedan ser justificadas jurídicamente.

\section{BIBLIOGRAFÍA CITADA}

Aguilera de Paz, Enrique (1917): Tratado de las cuestiones prejudiciales y previas (Madrid, Reus, segunda edición).

Alsina, Hugo (1959): Las cuestiones prejudiciales en el proceso civil (Buenos Aires, EJEA).

Aragoneses Martínez, Sara (1995): "La voz prejudicialidad (Do Procesal) en Enciclopedia Jurídica Básica (Madrid, Civitas).

ArmentA Deu, Teresa (2013): "Algunas reflexiones en torno a la convergencia entre los procesos civil y penal y la deriva común hacia métodos extrajurisdiccionales", en ARMENTA DEU, Teresa (coord.) La convergencia entre proceso civil y penal ¿una dirección adecuada? (Madrid, Marcial Pons, Ediciones Jurídicas y Sociales) pp. 227-249.

Aróstica Maldonado, Iván (2008): "Los contenciosos administrativos especiales en la legislación chilena”, Ius Publicum, No 20: pp. 85-103.

Aróstica Maldonado, Iván (2011): "Los Tribunales que ejercen la justicia administrativa en el derecho chileno”, en Arancibia, Jaime, Martínez, José Ignacio y Romero, Alejandro (coords.), Litigación Pública (Santiago, AbeledoPerrot) pp. 119-150.

Atienza, Manuel (2006): Ilícitos atípicos (Madrid: Trotta, segunda edición).

Barros Bourie, Enrique (2007): Tratado de responsabilidad extracontractual (Santiago de Chile, Editorial Jurídica de Chile, reimp. de la primera edición).

Bermúdez Soto, Jorge (2014): Derecho Administrativo General (Santiago de Chile, AbeledoPerrot, tercera edición).

Cachón Cadenas, Manuel (2013): "Los modelos procesales civil y penal: perspectiva histórica en ARmentA Deu, Teresa (coord.) La convergencia entre procveso civil y penal (Madrid, Marcial Pons) pp. 11-33.

Calamandrei, Piero (1996): Instituciones de Derecho Procesal Civil, según el nuevo Código (trad. Santiago Sentís Melendo, Buenos Aires, El Foro).

Cano Campos, Tomás (2001): "Non bis in idem, prevalencia de la vía penal y teoría de los concursos en el derechos administrativo sancionador”, Revista de Administración Pública, No 156: pp. 191-249.

Cappelletti, Mauro (1968): Las sentencias extranjeras y las normas extranjeras en el proceso civil (Buenos Aires, EJEA).

Carocca Pérez, Alex (2008): "Efectos de la sentencias penales en procesos civiles” en RoDríguez, Luis (coord.), Delito, Pena y Proceso (Santiago, Editorial Jurídica de Chile) pp. 803-822.

Carpintero Benítez, Francisco (2012): La crisis del Estado en la Edad Postmoderna (Cizur Menor, Aranzadi). 
Carreras Llansana, Jorge (1962): "Preceptos procesales penales en las leyes civiles", en Carreras, Jorge y Fenech, Miguel, Estudios de derecho procesal (Barcelona, Boch) pp. 761-783.

Carretta Muñoz, Francesco (2013): La coherencia en el proceso civil (Santiago, LegalPublishing).

Chiovenda, Giusepe (1977): Principios de Derecho Procesal Civil, (trad. J. Casais y Santaló, Madrid, Reus, tercera edición italiana).

Cisterna Pino, Adolfo (2007): Acciones civiles en el nuevo proceso penal (Santiago, Librotecnia, reimp. primera edición).

Cordero Quinzacara, Eduardo (2014): Derecho Administrativo sancionador (Santiago, La Ley).

Cordón Moreno, Faustino (1996): Proceso Civil de Declaración (Pamplona, Aranzadi).

De La Oliva, Andrés (2010): Derecho Procesal Penal (Madrid, Centro de Estudios Ramón Areces, reimp. de la octava edición de 2007).

De León Villalba, Francisco Javier (1998): Acumulación de sanciones penales y administrativas (Barcelona, Bosch).

Elorriaga De Bonis, Fabián (2010): Derecho Sucesorio (Santiago de Chile, LexisNexis, segunda edición).

Fenech, Miguel (1978): El Proceso Penal (Madrid, Agesa, tercera edición).

Ferrada Bórquez, Juan Carlos (2012): "La responsabilidad civil de los funcionarios públicos en el juicio de cuentas", en VV.AA., La Contraloría General de la República. 75 años (1927-2012), (Santiago de Chile, CGR) pp. 299-316.

Gómez Bernales, Gastón (2005): "La reforma constitucional a la jurisdicción constitucional”, en ZúNIga, Francisco (edit.), Reforma constitucional (Santiago de Chile, LexisNexis) pp. 144.

Gómez Bernales, Gastón (2013): Las sentencias del Tribunal Constitucional y sus efectos sobre la jurisdicción común (Santiago, UDP).

Gómez Orbaneja, Emilio (2009). "Eficacia de la sentencia penal en el proceso civil”, en Derecho y Proceso (Madrid, Civitas) pp. 223-248.

Gómez Orbaneja, Emilio (1947): Comentario a la ley de Enjuiciamiento Criminal (Barcelona, Bosch).

GonZÁlez SÁnchez, José Luis (2002): Las cuestiones prejudiciales penales en el proceso civil (Madrid, La Ley).

Guerra, Susana (2011): "Imperium de las sentencias judiciales en Roma y en la actualidad", Revista de Derecho Privado, No 21: pp. 59-86.

Hanseen Tallar, Carlos (2007): La función jurisdiccional de la Contraloría General de la República de Chile (Santiago, LexisNexis).

Lara Arroyo, José Luis (2011): "Algunas reflexiones sobre el contencioso administrativo en Chile", en Arancibia, Jaime, Martínez, José Ignacio y Romero, Alejandro (coord.), Litigación Pública (Santiago de Chile, AbeledoPerrot) pp. 65-92.

Lazo, Santiago (1917): Código de Procedimiento penal. Orígenes. Concordancias y Jurisprudencia (Santiago, Poblete Cruzat Hnos.). 
Lazo, Santiago (1922): Los códigos de procedimiento civil. Orígenes, concordancias, jurisprudencia (Santiago de Chile, Poblete Cruzat Hnos).

Lemmo, Elio (1991): “Questioni pregiudiziali”, en Enciclopedia Giuridica (Roma).

Málaga Diéguez, Francisco (1999): La litispendencia (Barcelona, Bosch).

Martínez, Marcial (1910): "La cosa juzgada”, en VV.AA., Ciencias Jurídicas (Santiago, Imprenta, Litografía y Encuadernación Barcelona) pp. 1-151.

Mattirolo, Luis (1930): Tratado de Derecho Judicial (trad. Eduardo Ovejero, Madrid, Reus, primera edición).

Maturana Miquel, Cristián, y Montero López, Raúl (2012): Derecho Procesal Penal (Santiago, Thomson Reuters, segunda edición).

Menestrina, Francesco (1904): La Pregiudiciale nel proceso civile (Vienna, Manz).

Morcillo Moreno, Juana (2007): Teoría y práctica de las cuestiones prejudiciales en el ámbito del derecho administrativo (Madrid, La Ley).

Mortara, Aristo (1895): "Cosa juzgada penal y la acción civil", Revista General de Legislación y Jurisprudencia, vol. 43 no 87: pp. 5-47.

Nieva Fenol, Jordi (2010): La cosa juzgada (Santiago, AbeledoPerrot).

Pérez Gordo, Alfonso (1982): Prejudicialidad penal y constitucional en el proceso civil (Barcelona, Bosch).

Peyrano, Jorge W. (2010): Nuevas tácticas procesales (Rosario, Nova Tesis).

Picard, Nicola (2006): Manuale del Processo Civile (Milán, Giuffré Editore).

Proto Pisani, Andrea (2006): Lezioni di Diritto Processuale Civile (Nápoles, Jovene, quinta edición).

ReYNAL Querol, Núria (2006): La prejudicialidad en el proceso civil (Barcelona, J.M. Bosch).

Robles Reyes, Juan Ramón (2003): La Competencia jurisdiccional y judicial en Roma (Murcia, Universidad de Murcia; Servicio de Publicaciones).

Rojas Chamaca, Julio (2013): "Efectos reflejos de la sentencia condenatoria contra el imputado hacia los terceros civilmente responsables en el derecho procesal chileno", en Arancibia, Jaime; Martínez, José Ignacio y Romero, Alejandro (coord.), Precedente, cosa juzgada y equivalentes jurisdiccionales en la litigación pública (Santiago, AbeledoPerot) pp. 353-374.

Romero Rodríguez, Sophía (2013): "Concurso de normas y concurso de acciones en el Derecho procesal civil chileno", en Ius et Praxis, No 2: pp. 207-250.

Romero Seguel, Alejandro (2012): La cosa juzgada en el proceso civil chileno (Santiago, Editorial Jurídica de Chile, reimp.).

Rosenblant, Héctor (2000): Presentencialidad (Buenos Aires, Ad Hoc).

Ruiz Manero, Juan (2006): "Ilícitos atípicos" (Madrid, Trotta, segunda edición).

Satta, Salvatore (1971): Manual de Derecho Procesal Civil (trad. S. Melendo y F. de la Rúa, Buenos Aires, EJEA, séptima edición italiana).

Sierra Herreros, Alfredo (2013): Patentes de invención y Derecho del Trabajo. Régimen jurídico de las invenciones realizadas por el trabajador (Santiago, LegalPublishing-Thomson Reuters).

Silva IrarráZaval, Luis Alejandro (2013): "Poder Judicial y Tribunal Constitucional: la tensión que nace de las sentencias de inaplicabilidad”, en: Arancibia, Jaime; Martínez, 
José Ignacio y Romero, Alejandro (coord.), Precedente, cosa juzgada y equivalentes jurisdiccionales en la litigación pública (Santiago, AbeledoPerrot) pp. 185-198.

Somarriva Undurraga, Manuel (2002): Indivisión y Partición (Santiago, Editorial Jurídica de Chile, quinta edición).

Vallespín Pérez, David (2007): La prejudicialidad penal en el proceso civil y en el proceso concursal (Barcelona, CIMS).

Vergara Blanco, Alejandro (2011): "Esquema del contencioso administrativo: su tendencia hacia el modelo mixto y situación actual del recurso de protección”, en ARANCIBIA, Jaime; Martínez, José Ignacio y Romero, Alejandro (coord.), Litigación Pública (Santiago, AbeledoPerrot) pp. 37-51.

\section{NORMAS CITADAS}

Constitución Política de la República de Chile

Código Civil (CC)

Código de Procedimiento Civil (CPC)

Código Penal (CP)

Código Procesal Penal (CPP)

Código del Trabajo (CT)

Código Orgánico de Tribunales (COT)

Ley 18.055, sobre Mercado de Valores

Ley $N^{\circ} 20.780$, de 29 de septiembre de 2014, sobre Reforma Tributaria.

Ley $\mathrm{N}^{\circ} 19.496$ sobre protección a los derechos de los consumidores (reformada el 14 de julio de 2004 por la Ley No 19.955)

Decreto Ley (DL) 211 de 1973 (modificado por la Ley No 20.361 de 13 de julio de 2009).

\section{JURISPRUDENCIA CITADA}

Cárdenas Triviño con Corporación Universidad de Concepción (2011): Corte de Apelaciones. de Apelaciones de Concepción, de 28 de julio de 2011, MJ 28672.

Cayupi Cuevas, Carlai con Luengo Salvo, Zodemir y otra (2008): Corte Suprema, sentencia de 5 de marzo de 2008, Rol N 4788-06, MJ 16588.

Comunidad Los Campos de Cano Gallegos de los Andes con Sociedad de Inversiones e Inmobiliaria Sierra del Cóndor Ltda. (2008): Corte Suprema, 21 de octubre de 2008, Rol Nº 4670-07, MJ 18616

Contra Exequiel Elgueta Cárcamo, Pedro Antonio Elgueta Cárcamo, Cristián Nelson Cisternas Aguirre (2013): Corte Suprema, 30 de abril de 2013, Rol No 12553-2011.

Contra Mittersteiner Pig, Georgina Francisca (1994): Corte. de Apelaciones. de San Miguel, 23 de mayo de 1994, MJ 2523.

Contra N.N. (1989): Corte de Apelaciones de Concepción, 28 de julio de 1989, MJ 4523.

Contra Palma Ramos, José Renato (1990): Corte Suprema, 7 de mayo de 1990, MJ 4407.

Contra Vásquez Orellana, Eliana de Jesús (1991): Corte de Apelaciones. de San Miguel, 19 de noviembre de 1991. 
Constructora Grofman S.A. y otro cl Constructora VCGP Chile S.A. y otros (2012): Corte. de Apelaciones de Santiago, 21 de septiembre de 2012, MJ 33376.

Fisco de Chile con Inmobiliaria Caymaco del Pino Ltda. (2012): Corte Suprema, 3 de mayo de 2012, Rol 4808-09, MJJ31889.

Gold Nutrition Industria y Comercio (2008): Corte Suprema, 15 de septiembre de 2008 (exequátur)., Rol N 6615-07, MJ 18.606.

Guerra Tapia, Mario Raúls (2004): Corte Suprema, 27 de julio de 2004, Rol N 1670-04, MJ 8468.

Henríquez Gavilanes, Eliseo con Rojas Müller, Liliana (2006): Corte Suprema, 23 de octubre de 2006, MJ 8964.

Karl Salas, Elexis con Soza Soza Humberto (2008): Corte Suprema, 2 de julio de 2008, Rol $\mathrm{N}^{\circ}$ 2346-07, MJ 17587.

Letelier Pimentel, Orlando con Pimentel Pérez, Orlando e Inmobiliaria e Inversiones G.y A. S.A. (2011): Corte Suprema, 25 de mayo de 2011, Rol N 8950-09, MJ 27881.

Morales Riquelme, Jorge con I. Municipalidad de Pucón (2010): Corte Suprema, 24 de septiembre de 2010,. Rol No 3198-10, MJ 24826.

Moyano, Francisca con Hernández Pizarro, Hernán (2008): Corte Suprema,: 21 de enero de 2008, Rol 4196-06, MJ 16.536.

Odde Reyesm, Emma con Ramírez Inostroza, Bartolomé y otro (2009): Corte. de Apelaciones. de Talca, 20 de mayo de 2009., Rol No 66421-04, MJ 20296.

Palma Aravena, Soledad cl Comercial Nueva Suiza Ltda. (2011): Corte Suprema, 12 de agosto de 2011. MJJ28919

Pérez Mora, Rosa del Carmen con Santibáñez Oporto, Blanca Silvia y otra (2005): Corte Suprema, 26 de octubre de 2005, MJ 17593.

Philip Morris Chile con Empresas CCT S.A. (2011): Corte de Apelaciones. de Ap. de Santiago, 8 de noviembre de 2011, Rol No 1520-10, MJ 30101.

Quisheng Resources Limited con Minera Santa Fe (2014): Corte Suprema, 27 de marzo de 2014 (exequátur), Rol No 7.854-13.

Sáez Carrasco, Pilar (1982): Corte Suprema, 7 de junio de 1982, MJJ 5903.

Salgado Muñoz, Rosa con Concha Dolz, Claudia (2009): Corte Suprema, 26 de enero de 2009, ROL Nº 6466-08, MJ 19348.

Silva con Alvarado y Salmones Caleta Bay S.A. (2012): 19 de diciembre de 2012. Rol № 19 de diciembre de 2012, MJJ 34199

Sindicato de Trabajadores Catedral (2005): Corte Suprema, 19 de enero de 2005, MJ 15531.

Yarur Terre, María con Bois Courtade, Denis (2009): Corte Suprema, de 5 de agosto de 2009, Rol 4081-09, MJ 20.904.

Sentencia de 29 de diciembre de 2011 núm. 942/2011) de la Sala de lo Civil, Sección 1a del Tribunal Supremo español. 